\title{
Asymmetric Dynamic Conditional Copula Correlation and Fundamental Determinants of Interest Rate Comovement
}

\author{
Priyanshi Gupta ${ }^{1+}$, Sanjay Sehgal ${ }^{2}$ \\ ${ }^{1}$ CHRIST, India \\ ${ }^{2}$ University of Delhi, India
}

\begin{abstract}
We study time-varying interest rate comovement and its determinants for the retail banking sector in the euro area over pre-crisis and during crisis, between 2003 and 2018. The analysis is conducted for 11 euro area countries, each classified as either core or periphery. Copula Asymmetric DCC-GARCH is estimated for each country-pair to measure the dynamic interest rate correlations for deposits and loans to households. We then examine the determinants by regressing quarterly correlations on macroeconomic and cross-border linkages, banking, and sociological variables. We also assess the impact of the two crises and of policy initiatives, including negative interest rate, Single Supervisory Mechanism, and Single Regulatory Mechanism. Different panel regressions reveal limited, although varied, influence of determinants on correlations across different products, maturities, and country groups. We conclude that the intrinsic features of the retail banking industry, such as customers' trust, information asymmetry, and political influence, hinder strong interest rate convergence in the euro area.
\end{abstract}

Keywords: ADCC GARCH, Euro area, Core and periphery, Determinants of convergence, Retail banking integration, Panel regression

JEL Classifications: C2, F3, G21

Received 12 May 2019, Revised 8 September 2019, Accepted 5 November 2019

\section{Introduction}

At the recent "The Euro at 20" conference organized by the Central Bank of Ireland and the IMF, IMF's managing director Christine Lagarde stated, "At age 20, the euro area is more mature," adding that three key areas to further improve the resilience of the euro area are the completion of the banking union, "truly integrated" financial and capital markets, and greater fiscal risk sharing. ${ }^{1)}$ Over these past 20 years, banking in the euro area has witnessed some momentous events, including the introduction of the euro currency (2002), the twin crises (the Global Financial Crisis and the European Debt Crisis) over 2007 2014, and concrete policy initiatives toward banking

\footnotetext{
+Comesponding Author: Priyanshi Gupta

Assistant Professor, Institute of Management, CHRIST (Deemed to be University) Hosur Rd, Bengaluru, Karnataka-560029, India, Tel: +91-8879252473, Email: priyanshiguptadu@gmail.com

Co-Author: Sanjay Sehgal

Professor, Department of Financial Studies, University of Delhi, South Campus, New Delhi-110021, India.

Tel: +91-98911-99840, Email: sanjayfin15@yahoo.co.in
} 
union since 2014. The financial crises revealed the gaps in competitiveness across member countries, their heavy indebtedness, and unsustainable debt burden on the banking sector. These, in turn, raised questions on the joint consequences of a banking union for the region's taxpayers. Three main issues are addressed in this study: (1) How have the interest rate comovements changed in the euro area's retail banking sector in the post-euro era from pre-crisis period (2002 2007) to the crisis period (after 2007)? (2) Is the degree of interest rate comovement related to country-specific characteristics? (3) What are the fundamental factors that drive the comovement of interest rates across countries and over time?

The present study addresses these issues by estimating correlations of interest rates and examining their determinants with six categories of retail banking products (deposits and loans) and households in 11 euro area countries, each of which is classified as either core or periphery, during both the non-crisis and the crisis periods from 2003 to 2018. This study focuses on the household clientele of retail banks, which contributes the highest to the net national income (82\%); net disposable income (73\%); and net saving (91\%) of the euro area. ${ }^{2}$ ) The long-term process of convergence of the banking sector includes cross-border comovements of banking interest rates, which, in turn, influence the saving and credit behavior of households in their respective countries.

Although the literature on the factors driving the comovement of returns in stock and bond markets is extensive (e.g., Bracker and Koch 1999, Kim et al. 2005, Buttner and Hayo 2011, Narayan et al. 2014, Gupta et al. 2015, Mobarek et al. 2016, Perego and Vermeulen 2016), there are few research studies on the factors driving comovements in the banking interest rates in sectors across borders. This study attempts to address this research gap. Further, it contributes to the literature as we use comprehensive data that cover six interest rate series on deposits, consumer loans, and mortgage for different maturities.

Further, the study does not address the heterogeneity in banking integration among the various core and periphery markets, while several studies have shown that emerging capital markets are more segmented than developed ones (e.g., Christoffersen et al. 2012, Bekaert et al. 2014). For instance, van Rijckeghem and Weder (2003) examine volatility spillover through the lending channel of banks; however, the study does not address the transmission interlinkages among and across country groups. This study addresses this research gap by estimating time-varying correlations of interest rates and their determinants over normal and crisis subperiods and across the core and periphery groups of euro area economies.

We estimate the dynamic interest rate comovement using Copula Asymmetric Dynamic

1) Euro 2.0: Past, Present, and Future of Euro Area Integration, (June 25, 2018), https://www.imf.org/en/News/Articles/2018/06/22/sp062518-euro-area-integration

2) Eurostat 2015. Contributions of Each Institutional Sector to Macroeconomic Developments. http://ec.europa.eu/eurostat/web/sector-accounts/detailed-charts/ contributions- sectors. 
Conditional Correlation (ADCC) GARCH. The use of this model enables the study of asymmetric dependence structures between random variables, without requiring the assumption of joint normality. We then investigate the factors (macroeconomics, banking, linkage, and sociology) driving these correlations by estimating fixed-effect panel regression for each type of interest rate separately. This understanding is crucial for policymakers and other participants in the financial system. Identifying the factors driving interest rate convergence helps the policymakers to influence the pass-through effects of policy intervention by the customization of policies on the basis of fundamentals across different groups (e.g., the periphery and the core countries in the euro area). Optimal national-level policies and their coordination at the level of the monetary union and toward fulfilling the goal of SFM can be implemented, particularly in the aftermath of the crisis.

The study is presented as follows. Section 2 reviews the literature. Section 3 deals with the first two research questions on the measurement of the progress of banking integration over normal and crisis periods for core and periphery countries. Under Section 3, different subsections elaborate on the indicators used and their methodology, the data used, and the empirical results. Section 4 addresses the third research question on the identification of potential determinants of retail banking integration during crisis and the non-crisis periods. The final section concludes.

\section{Literature Review}

The comovement of returns and asset prices across borders has attracted continued academic interest because it impacts portfolio diversification and the convergence of financial markets. While the returns comovement in stock markets and bond markets has been widely studied, the lack of literature on the comovement of interest rates in the retail banking sector is telling. Further, the existing literature remains inconclusive on the progress of banking interest rate comovements. The elimination of exchange-rate volatility and process toward monetary unification contributed to the integration of financial markets in the region (Kim, Moshirian and $\mathrm{Wu} 2005$, Bartram, Taylor and Wang 2007). While the integration of wholesale banking is considered to be almost complete in the EMU, the integration of retail banking is still under progress (Guevara Moudos and Perez 2007). Sehgal et al. (2016), Eppendorfer et al. (2003), and Cabral et al. (2002) observed a weak level of integration in retail banking in the euro area. Barros et al. (2005) noted an inclination toward higher cross-border European banking activity through the creation of subsidiaries rather than doing so through branches, which points to the continued existence of significant barriers to full market integration. On the other hand, Perez et al. (2005) and Sørensen and Gutiérrez (2006) observed greater progress of retail banking integration following the introduction of the euro. Similar observations were made by Brasili and Vulpes (2005), who analyzed comovements in bank risk for large European banks during 1994 2003 
by decomposing the risk into EU-wide, country-specific, and bank-level components. The EU-wide component gained importance following the introduction of the euro in 1999, particularly for large banks. There is also evidence of different paces of convergence across product types. For example, Gropp et al. (2014) and Rughoo and Sarantis (2012, 2014) found that interest rates on loans converge faster than those on deposits because of faster adjustment of interest rates on loans. However, Rughoo and Sarantis $(2012,2014)$ noted a divergence in the transition paths at the onset of the 2008 financial crisis.

With respect to the second strand of research on the determinants of retail banking sector integration, again, suffice it to say that most of this research is concentrated on the factors driving the comovement of capital markets (e.g., Buttner and Hayo 2011, Baele et al. 2010, Piljak 2013, Narayan et al. 2014, Mobarek et al. 2016, Sehgal et al. 2018) and that little exists in the empirical literature on the factors driving banking integration (Perez et al. 2005, Mayordomo et al. 2015). Bracker et al. (1999) used other variables such as relative exports and imports and the difference of inflation and real interest rates as determinants. Kim et al. (2005) considered financial variables to be the most significant determinants of the within-country stock-bond return correlation, while Kim et al. (2006) found monetary variables to be weakly significant. Similarly, Andersson et al. (2008) found macroeconomic variables and stock market uncertainties to be only weakly significant. Mayordomo et al. (2015) found that counterparty risk, financial cost, banking sector openness, size of financial sector, and debt are the most significant determinants of fragmentation in the European financial sector (including banking). The present study explores the different types of fundamental factors and classifies these potential determinants under different heads (see Table 2 for the detailed descriptions).

\section{Estimating Comovements}

This section introduces the data, explains the estimation methodology, and presents the results of the estimated dynamic conditional correlations of interest rates, which are then used for the panel regressions in Section 4. We use the Copula Asymmetric DCC-GARCH (Copula ADCC GARCH) model to estimate time-varying correlations. This enables the study of asymmetric dependence structures between random variables. ADCC captures time-varying correlations, while controlling for the asymmetric impact of joint bad news on volatility and correlation.

\section{A. Method}

This study employs a Copula DCC-GARCH for all possible country pairs. For the multivariate regression, the correlation matrix of all the possible country pairs is estimated (Table 1). 
Although the Copula DCC-GARCH is estimated on daily data, for the multivariate panel regression in this study under Section 4, the correlations are expressed at quarterly frequency by averaging daily dynamic correlations over the quarter. This helps in investigating the determinants of dynamic correlations at a frequency that is compatible with macroeconomic variables.

\section{Asymmetric dynamic conditional correlation model}

We follow Cappiello et al. (2006) and estimate ADCC with an Exponential GARCH (EGARCH) model. This model accounts for heteroscedasticity and continuously adjusts for time-varying volatility. While EGARCH accommodates the asymmetries in conditional variances of individual interest rate series, ADCC explains the asymmetry in correlations.

The mean equation is specified as an AR (1) process (on the basis of SIC criteria):

$$
r_{i, t}=\alpha_{i}+\sum_{k=1}^{n} \beta_{i, k} r_{i, t-k}+\varepsilon_{t}
$$

where $r_{t}$ represents the respective series on interest rate movement and $\varepsilon_{t}=\left(\varepsilon_{i, t}, \varepsilon_{E M U, t}\right)$, $\varepsilon_{t} \mid \beth_{t-1} \sim N\left(0, H_{t}\right) . H_{t}$ is the $(n \times n)$ condition + al covariance matrix, decomposed as

$$
H_{t}=D_{t} R_{t} D_{t}
$$

where $D_{t}$ is the $\left(\begin{array}{lll}n & x & n\end{array}\right)$ diagonal matrix of time-varying standard deviations for the interest rates, obtained by estimating the GARCH $(1,1)$ process that generates conditional variance of the residuals from the mean equation. $R_{t}$ is the time-varying correlation matrix obtained as:

$$
R_{t}=\operatorname{diag}\left(Q_{t}\right)^{-1 / 2} Q_{t} \operatorname{diag}\left(Q_{t}\right)^{-1 / 2}
$$

The evolution of the correlation equation in ADCC model (Cappiello et al. 2006) is given by:

$$
Q_{t}=\left(1-\theta_{1}-\theta_{2}\right) \bar{Q}-g \bar{N}+\theta_{1}\left(\varepsilon_{t-1} \varepsilon_{t-1}^{\prime}\right)+\theta_{2} Q_{t-1}+g\left(\eta_{t-1} \eta_{t-1}{ }^{\prime}\right)
$$

where $Q_{t}=\left(q_{i j, t}\right)$ is the $(n \times n)$ symmetric positive definite matrix of $\varepsilon_{t}, \bar{Q}=E\left(\varepsilon_{t} \varepsilon_{t}^{\prime}\right)$ is the $(n \times n)$ unconditional correlation matrix of the standardized residuals $\varepsilon_{t}, \bar{N}=E\left(\eta_{t} \eta_{t}{ }^{\prime}\right)$, and the asymmetric term $g$ captures the periods where both markets jointly experience negative shock. The scalar parameters $\theta_{1}$ and $\theta_{2}$ are non-negative and satisfy $\theta_{1}+\theta_{2}<1$. 


\section{Copula ADCC GARCH}

Given that the assumptions of linear dependence and multivariate normality of distribution of standardized innovations are not necessarily satisfied (for more details, Kotkatvuori-Örnberg 2016), this study uses the Copula GARCH-DCC model to obtain estimates of dynamic correlations between the interest rate comovement among all possible pairs of sample countries. According to Sklar's (1959) theorem, a unique $n$-dimensional copula exists as a function that links marginal distributions into a multivariate joint distribution function. Patton (2006) investigated the extension of the static copula approach to dynamic models such as GARCH and proved the validity of the Sklar (1959) theorem under conditional case settings. As explained in Kotkatvuori-Örnberg (2016), the theory gives a vector of standardized residuals $\varepsilon_{t}=\left\{\varepsilon_{1}, t, \varepsilon_{2}, t, \ldots, \varepsilon_{k, t}\right\}$ of the joint $k$-dimensional distribution function $H$, with margins $F_{1}, F_{2}, \ldots, F_{k}$, transformed into uniform distribution by the probability integral transformation method as follows:

$$
u_{i, t}=F\left(\varepsilon_{i, t}\right) \text { with } u_{i, t} \sim U[0,1]
$$

The joint distribution function of the standardized residuals can be presented as follows:

$$
H\left(\varepsilon_{1, t}, \varepsilon_{2}, t, \ldots, \varepsilon_{k, t}\right)=C\left(F_{1}\left(\varepsilon_{1}, t\right), F_{2}\left(\varepsilon_{2, t}\right), \ldots, F_{\mathrm{k}}\left(\varepsilon_{k, t}\right)\right)
$$

where a $k$-variate copula, $C$, links marginal distributions to a joint distribution function. The copula $C$ is given as follows:

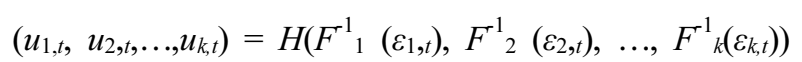

It is determined for any absolutely continuous marginal distributions, where the dependence relationship is determined by the copula, with the shape being determined by the marginal distributions.

A copula adapted in the standard multivariate normal distribution gives a Gaussian copula. This study uses Gaussian bivariate copula to link the marginal distributions of interest rate movement in countryi and the interest rate movement in countryj to the joint distribution. This bivariate Gaussian copula is as follows:

$$
C\left(u_{1, t}, u_{2, t}\right)=\left(\varphi^{-1}\left(\varepsilon_{1}, t\right), \varphi^{-1}\left(\varepsilon_{2, t}\right)\right)
$$

where a given correlation matrix $R \in R^{2 \times 2}$ is the joint cumulative distribution function of a multivariate standard normal distribution and $\varphi^{-1}$ is the inverse of the univariate cumulative 
distribution function of a standard normal distribution. The Gaussian bivariate copula density function can be stated as follows:

$$
C\left(u_{1}, u_{2}\right)=\frac{1}{\sqrt{\operatorname{det} R}} \exp \left(-\frac{1}{2}\left(\begin{array}{l}
\varphi^{-1}\left(u_{1}\right) \\
\varphi^{-1}\left(u_{2}\right)
\end{array}\right)^{T} R^{-1}-1\left(\begin{array}{l}
\varphi^{-1}\left(u_{1}\right) \\
\varphi^{-1}\left(u_{2}\right)
\end{array}\right)\right)
$$

where $I$ is the identity matrix.

\section{B. Data}

\section{The sample countries and their classification}

Our sample consists of 11 European countries that are the oldest members of the euro area. ${ }^{3}$ ) These countries are classified as the "core" and the "periphery" groups.4) Austria (AUT), Belgium (BEL), France (FRA), Finland (FIN), Germany (DEU), and the Netherlands (NLD) constitute the core group, while Greece (GRC), Italy (ITA), Ireland (IRL), 5) Portugal (PRT), and Spain (ESP) are classified under the periphery group. This classification is in line with studies by Anastasiou et al. (2016), De Santis and Cesaroni (2016), and the ECB (2017). The classification reflects the difference in stress experienced in these groups as the periphery economies of GIIPS experienced significant deterioration in credit rating since the end of 2008 (Perego and Vermeulen 2016). In addition, the levels of income per capita of all periphery countries are lower than those of the core countries and below the average of the euro area.

The first motivation for this classification lies in the need to check the generally held view that high-income economies are more likely to integrate with other economies.6) Second, as is well known, for policy intervention to be effective, the integration measurement should

3) These countries form the founding members of the monetary union. The only exception is Greece, which joined the euro zone in 2001. Greece is included in the sample for two reasons: first, it joined the euro relatively earlier than the other nonfounding members, which joined from the year 2007 onward; and second, any analysis on the European Debt Crisis is incomplete without considering Greece. We exclude Luxembourg owing to limited data availability for the study of determinants.

4) The respective economic situations in these countries vary and bundling them in one of the groups may dilute this fact. However, we seek to find general trend of convergence progress in the region, across core versus periphery economies. Further, in the second part of this study, for the purpose of determinants analysis, macroeconomic data for each country are considered separately, hence the information on economic situation is not completely lost.

5) Some studies classify Ireland in the core group based on geographical classification of northern euro area (core) and southern euro area (periphery). However, majority of the literature (e.g., Schmitz and von Hagen 2011, Grammatikos and Vermeulen 2012, Ahlborn \& Wortmann 2018) bundle Ireland together with the other periphery countries in the euro area. The seminal work of Bayoumi and Eichengreen (1993), as well as recent studies (e.g., Campos \& Macchiarelli 2016) revisiting the original work, classify Ireland in the periphery group. In the popular media, too, the acronym used for periphery economies of the euro zone, "GIIPS," bundles Ireland with the "southern" countries of Greece, Italy, Portugal, and Spain.

6) Often attributed to higher cross-border capital flows as they typically have more stable macroeconomic policies, lower credit risk, better institutional architecture, and deeper markets. 
account for distinctions owing to divergent developments in financial markets across the bloc.

Given the sample of 11 countries, the maximum number of country pairs is 55. However, the number of country pairs included under each deposit and lending category depends on the data availability. Table 1 provides an overview of data availability and the number of correlations in each category.

Table 1. Data availability and country pairs

\begin{tabular}{|c|c|c|c|c|c|c|c|c|c|c|c|c|c|c|}
\hline Category & Maturity & $\begin{array}{l}\text { Category } \\
\text { Indicator }\end{array}$ & Aus & Bel & Fin & Fre & Ger & Net & Gre & Ire & Ita & Por & Spn & $\begin{array}{c}\text { No. of } \\
\text { Correlation } \\
\text { Pairs }\end{array}$ \\
\hline Deposit & $\begin{array}{l}\text { up to } 1 \\
\text { years }\end{array}$ & STD & 0 & 0 & 0 & 0 & 0 & 0 & 0 & 0 & 0 & 0 & 0 & 55 \\
\hline Deposit & $\begin{array}{c}1-2 \\
\text { Years }\end{array}$ & MTD & 0 & 0 & 0 & 0 & 0 & $x$ & 0 & 0 & 0 & $x$ & 0 & 36 \\
\hline Deposit & $\begin{array}{c}\text { over } 2 \\
\text { years }\end{array}$ & LTD & 0 & 0 & 0 & 0 & 0 & 0 & $x$ & $x$ & 0 & $x$ & 0 & 28 \\
\hline $\begin{array}{l}\text { Consumption } \\
\text { Loans }\end{array}$ & $\begin{array}{l}\text { up to } 1 \\
\text { year }\end{array}$ & STL & 0 & 0 & 0 & 0 & 0 & $x$ & 0 & 0 & 0 & 0 & 0 & 45 \\
\hline $\begin{array}{l}\text { Consumption } \\
\text { Loans }\end{array}$ & $\begin{array}{c}1-5 \\
\text { Years }\end{array}$ & MTL & 0 & 0 & 0 & 0 & 0 & $x$ & 0 & 0 & 0 & 0 & 0 & 45 \\
\hline $\begin{array}{l}\text { Mortgage } \\
\text { Loans }\end{array}$ & $\begin{array}{l}\text { up to } 1 \\
\text { year }\end{array}$ & STM & 0 & 0 & 0 & 0 & 0 & 0 & 0 & 0 & 0 & 0 & 0 & 55 \\
\hline $\begin{array}{l}\text { Mortgage } \\
\text { Loans }\end{array}$ & $\begin{array}{c}1-5 \\
\text { Years }\end{array}$ & MTM & 0 & 0 & 0 & 0 & 0 & 0 & $x$ & 0 & 0 & $x$ & 0 & 36 \\
\hline $\begin{array}{l}\text { Mortgage } \\
\text { Loans }\end{array}$ & $\begin{array}{l}5-10 \\
\text { Years }\end{array}$ & LTM & 0 & 0 & 0 & 0 & 0 & 0 & $x$ & $x$ & 0 & $x$ & 0 & 28 \\
\hline
\end{tabular}

\section{The interest rate series}

The data used for this study are interest rates on deposits, consumer loans, and mortgage loans to households. These data are harmonized7) monthly, with MFI interest rates database acquired from Datastream European Central Bank (ECB). Monthly data are collected over the sample period from January 2003 to September 2018, which gives a total of 191 observations per series. As for the credit side, two subcategories of products with different maturities are considered: consumer loans and mortgage loans. The six interest rate series used are as follows: ${ }^{8)}$

a. Deposit rates with maturities up to 1 year or up to 2 years.

7) In the harmonized database, the bank interest rate series within each instrument category are based on same definitions and classifications across all member countries. Hence, there is no inherent heterogeneity in the data unlike the bank interest rate statistics prior to 2002 .

8) We have limited the analysis only to short-term and medium-term maturities as data availability for longer maturities is systematically related to country characteristics (core vs periphery), which might affect the analysis. While the data on longer term maturities is available for core group countries, it is not available for most of the periphery group countries. We thank the anonymous reviewer for this observation. 
b. Loans for consumption with maturities up to 1 year or 1-5 years.

c. Lending for house purchases with maturities up to 1 year or 1-5 years.

The movement in interest rates is computed as a monthly percentage point change in the interest rates. The stationarity of the interest rate change is confirmed by conducting the ADF tests (Table 3).

The sample period is classified into the crisis (during the crisis) and non-crisis periods (before and after the crisis period). For the purposes of this study, the period is identified from August 2007 to September 2009 as the global financial crisis (GFC). Banking interest rates, unlike the prices of capital market securities, are not purely driven by market and government policy, and central bankers influence the movement of bank interest rates. Hence, to determine the demarcation, information from both the empirical evidence (Gorton et al. 2014, Dungey and Gajurel 20159) ) and the ex-post chronologies ${ }^{10)}$ that is based on announcements of the dates of actions taken by the government and the central bank, along with the Bank of International Settlements, Federal Reserve Bank of St. Louis, the Bank of England, and the European Central Bank, is considered reliable. ${ }^{11)}$ The study timeline is also in agreement with that of Angelini et al. (2011) and Mobarek et al. (2016), who consider the GFC from 2007Q4, which was marked by BNP Paribas ceasing its banking operations on August 9, 2007.

Further, the period from October 2009 to December 2013 is considered to be the main phase of the European debt crisis (EDC) (Kratochvíl and Sychra 2019), which was triggered by the exposure of weak and unstable fundamentals in Greece. However, given the limited number of observations, GFC and EDC are combined as the "crisis period." Thus, the period from August 2007 to December 2013 is termed the "crisis period," and the period from 2003 to July 2007, as well as that from January 2014 to September 2018, is termed the "non-crisis period."

\section{Results}

For presentation purposes, the estimated pairwise correlations for each category are averaged. In Figure 1, the plots show the average interest rate correlations for different groups (all countries, core-only, periphery-only, and mixed) over the sample period. For each category,

9) The estimation by Gorton et al. (2014) locates the breakpoint for repo spreads as July 23, 2007 and that for other money market instruments (CP, Fed funds, LIBOR) as August 7, 2007. Dungey and Gajurel (2015) detect structural change in variance of an individual return series of banking sector indices on July 19, 2007 and identify it as the start of crisis period.

10) The ex-post chronologies based on government and central bank's actions identify August 9, 2007 as the beginning of GFC.

11) Bank of International Settlements (BIS, 79th Annual Report, retrieved from http://www.bis.org/publ/arpdf/ar2009e2.pdf); The Federal Reserve Bank of St. Louis' chronology (http://timeline.stlouisfed.org/index.cfm?p=timeline), the Bank of England's chronology (http://www.bankofengland.co.uk/publications/Documents/fsr/2009/fsrannex0906.pdf); and the European Central Bank's crisis chronology (https:/www.ecb.europa.eu/ecb/html/crisis.en.html). 
a band is plotted that shows the minimum and maximum. These plots of dynamic correlations provide interesting insights into interest rate movements over time in different product and maturity categories, as well as for different country groups. In general, the plots reveal weak interest rate correlations in the euro area's retail banking sector.

Panel 1 of Figure 1 shows that correlations of interest rates on deposits of different maturities

Figure 1. Monthly dynamic conditional correlations estimated using Copula ADCC GARCH model

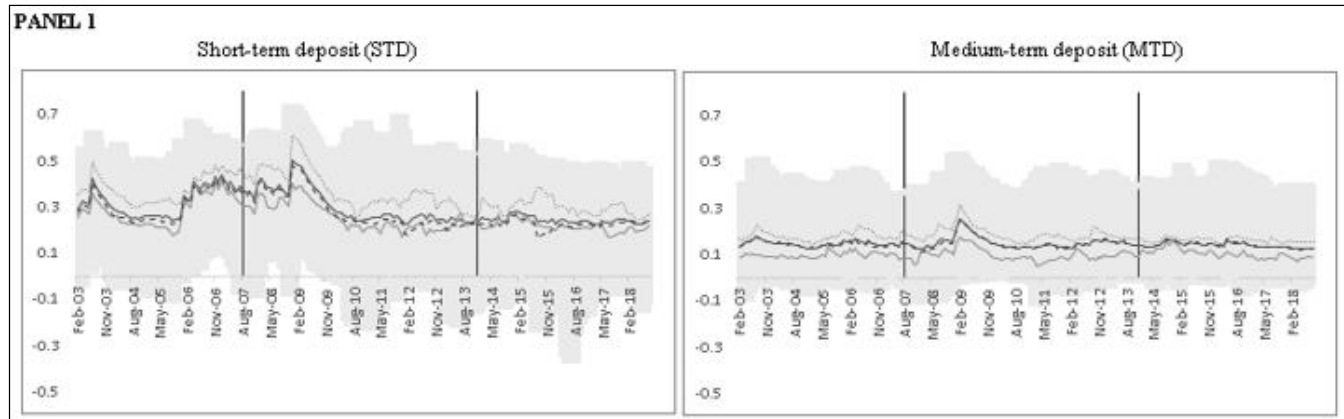

PANEL 2
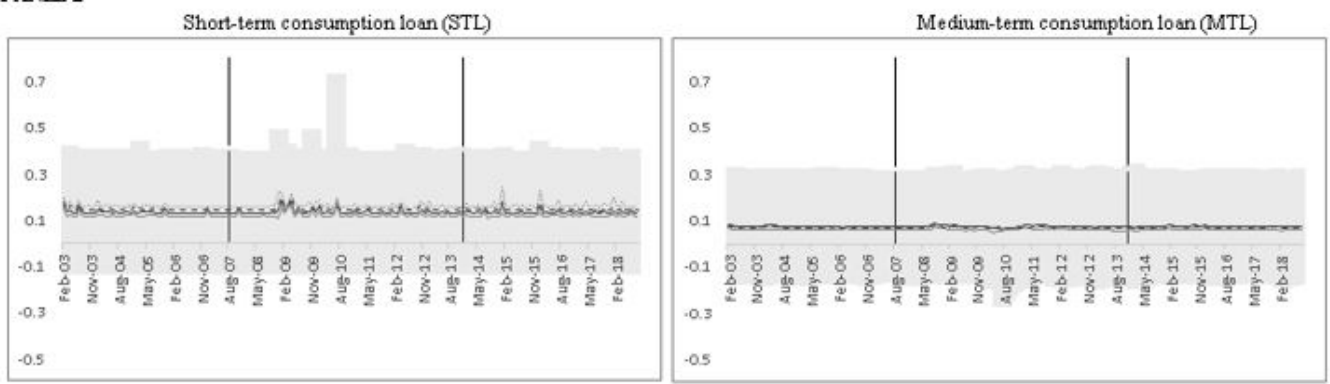

PANEL 3
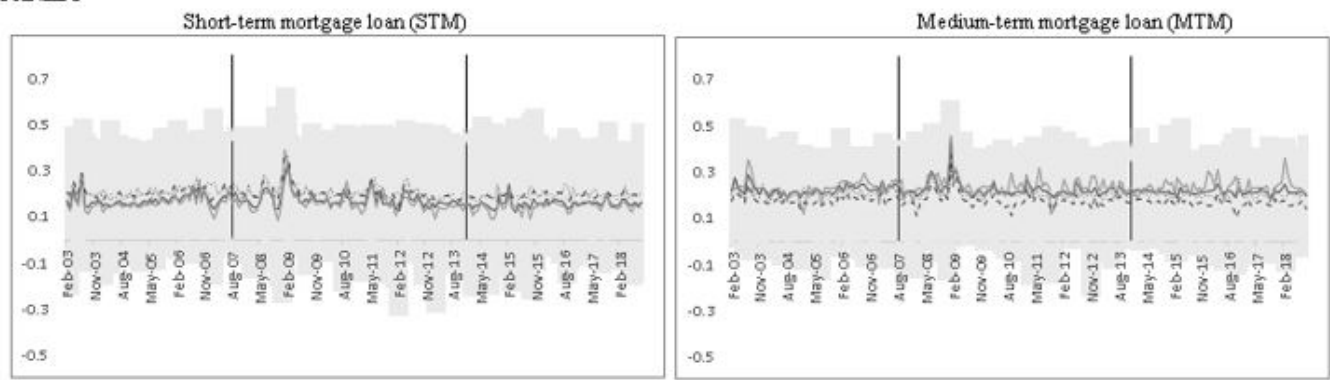

This figure shows the average monthly dynamic conditional correlation for all countries pair, for

core-only countries pair, for periphery-only countries pair and for mixed countries pair, for each interest rate category separately.

Shaded areas denote the minimum and the maximum for

Legend:

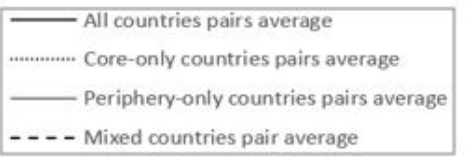
every category at each point in time. The area between the two vertical lines covers "crisis. period" and the rest is "noncrisis period". 
can be compared. Short-term interest rates are more correlated than longer-maturity deposit rates. Further, it can be seen that correlation is the highest among core-only countries and the lowest in the periphery group. This can be attributed to higher financial linkages among core countries because of similar standards of institutional structures and procedures and comparable attributes of relatively stable macroeconomic systems. Further, correlations appear to increase during the GFC, and are highest during the latter part of the GFC. This can be explained by the joint reaction of the countries to the crisis in the form of interest rates cuts to improve liquidity conditions. However, with the start of the EDC in the second quarter of 2009 , as the risk perceptions regarding periphery countries deteriorated, the correlations start decreasing. The interest rate correlations continued to remain subdued until the end of the sample period, regardless of the introduction of unconventional monetary policy (UMP) of negative interest rates in June 2012, the implementation of the Single Supervisory Mechanism, the setting up of the Single Resolution Framework in 2014, and the reported end of the recession in the euro area in 2016. Similar patterns of time-varying dynamics and comparative group dynamics are observed in the interest rate correlations for the medium-term deposits category.

Panel 2 of Figure 1 on consumption loans segment reveals an overall weak degree of interest rate correlation. In fact, the interest rate correlation for medium-term consumption loans is the weakest across all categories of savings and credit products. This finding is consistent with that of Rughoo and Serantis $(2012,2014)$. This particular weakness in the interest rate correlation for consumption loans can be attributed to the highly non-standardized nature of these products when compared with savings products, which are more standardized with limited and broad-based product differentiation (e.g., gender-based or age-based). Further, credit for consumption purposes is also subject to heterogeneity in borrowers with respect to the purpose of borrowing; wide differences in the cultural norms across countries regarding personal loans; borrower creditworthiness; the resulting information asymmetry between banks and borrowers, particularly in cross-border operations; and the disparity in lending controls exercised by banks.

Further, it is observed that in what is similar to deposits, the interest rate correlations in consumption loan categories show a similar pattern of stronger correlations in core-only groups when compared with other country groups and an increase in correlations during the GFC. While the interest rate correlations for medium-term consumption loans decreased during the EDC, no drastic change is observed in the case of the short-term category of consumption loans. Similarly, the interest rates on shorter maturity loans show a higher correlation. These findings on the inverse relationship between the degree of correlation and maturity are consistent with those of Rughoo and Serantis (2014). It should be noted that maturity has a bearing on the determination of the market rate because a longer maturity is associated with an increased risk factor. Thus, long-term rates include a premium, depending on the varying degrees of incremental risk, which has the effect of introducing heterogeneity in these rates. 
Panel 3 of Figure 1 presents the interest rate correlations for mortgage loans. Similarly, weak correlation and similar time-varying dynamics of correlations are observed, irrespective of the maturity type.

In general, the results of the measurement of integration reveal considerable heterogeneity in retail banking to households. This is consistent with the findings of previous studies (Bondt et al. 2005, Kleimeier and Sander 2006, Rughoo and Serantis 2012, 2014) that conclude that there exists weaker integration in the euro area's retail banking segment despite the removal of exchange rates, the establishment of a central bank, and the provision of smoother operations of cross-border branches. This may be attributed to the unique strengths and challenges of the retail banking segment. Retail banking relies heavily on personalized services, particularly in the case of households, thereby hampering standardization. Moreover, consumer trust and access to confidential information on households' creditworthiness play important roles. Martın-Oliver et al. (2005) present empirical evidence that information differentiation is an important variable leading to persistent dispersion across Spanish retail banking interest rates on both sides: credit and deposit.

The next section examines the drivers or determinants of these correlation dynamics.

\section{Estimating Determinants}

\section{A. Estimation technique}

The present study investigates into whether the determinants of interest rate correlations are macroeconomic, cross-border linkage-driven, specific to banking, or sociological by the estimation of panel regression, which allows for time-fixed effects to control for common shocks (Wälti 2011, Mobarek et al. 2016). The following panel linear regression model is estimated:

$$
\rho_{i, j, t, c}=\alpha_{t}+\dot{\beta}_{p}^{\prime} x_{i, j, t, c}+\varepsilon_{i, t}
$$

The dependent variable, $\rho_{i, j, t, c}$, is the Fischer-transformed quarterly Copula DCC-GARCH correlation for each country-pair, $i, j$, for each quarter, $t$, and each category, $c$. For the purpose of this regression, the monthly DCC estimates (estimated in Section 3) are averaged over the quarter and then Fisher-transformed. ${ }^{12}$ ) The frequency of this quarterly component is now the same as those of country-specific independent variables, which are mostly unavailable at a

12) The original correlation series are bounded between minus one and one. $\rho_{i, j, t, c}$ is unbounded correlation series obtained by Fisher-transformation. 
higher-than-quarterly frequency. $\alpha_{t}$ captures the time-fixed effects included for each regression. $x_{i, j, t, c}$ is a constant set of explanatory variables, which are discussed further. Each equation $c$ is separately estimated for each category of interest rates and for all possible country pairs (Table 1), over about 63 quarters.

The independent variables are as follows:

$$
x_{i, j, t, c}=\left[M_{i, j, t} L_{i, j, t} B_{i, j, t} S_{i, j, t}\right]
$$

where $M_{i, j, t}$ denotes the absolute difference in country-specific macroeconomic variables between country $_{i}$ and country $y_{j}$ at time $t$. These macroeconomic variables include $d G D P_{i, j, t}, d \operatorname{Inf} f_{i, j, t}$, $d P$ debt $_{i, j, t}$, dBudget $t_{i, j, t}$, and $d$ FinStress $_{i, j, t} . d G D P_{i, j, t}$ is the absolute difference between the quarterly growth rate of real GDP; $d \operatorname{Inf}_{i, j, t}$ is the absolute difference between the quarterly inflation rates; $d P$ debt $_{i, j, t}$ captures the absolute difference in quarterly public debt as a percentage of GDP; dBudget $_{i, j, t}$ is the absolute difference in quarterly government budget balance (surplus (+) / deficit(-)) as a percentage of GDP. dFinStress $s_{i, j, t}$ is the absolute difference in the quarterly Financial Stress Index. Together, these growth and stability indicators capture the essence of the Maastricht criteria for EU membership ${ }^{13)}$ as well as that of the Stability and Growth Pact. ${ }^{14)} L_{i, j, t}$ denotes the external linkage indicators between country $y_{i}$ and country $y_{j}$ at time $t$. These include BiTrade $e_{i, j, t}$ which is the quarterly weighted average bilateral trade size between country $y_{i}$ and country $_{j}$, and $B C S_{i, j, t}$, which captures the quarterly degree of business cycle synchronization between country and country $y_{j} . B_{i, j, t}$ denotes the absolute difference in the retail banking industry's indicators between country $_{i}$ and country $y_{j}$ at time $t$. These include $d$ BankRisk $_{i, j, t}$, dBankDev $v_{i, j, t}$, and $d$ BankSupInd $_{i, j, t}$, which measure the absolute difference between country $_{i}$ and country $y_{j}$ in the banking sector's riskiness, development, and independence of banking supervisors, respectively. The degree of the banking sector's riskiness indicates the stability and depth of the banking system and width of its exposure. Given the socioeconomic importance of the banking sector, it is prone to politically motivated interventions by governments. Independence of banking supervisor is an indicator of its ability to pursue optimal policies for the country's banking sector. Finally, $S_{i, j, t}$ captures the sociological variables, including Culture $i_{j, t}$ and Langauge $_{i, j, t}$. Given the diverse nature of retail consumers that retail banking serves, differences in cultural and sociological aspects across borders pose important challenges for banking integration. Culture $e_{i, j, t}$ is the difference in the cultural index country $_{i}$ and country $y_{j}$. The index is constructed on the basis of the study by Kogut and Singh (1988) and uses data on Hofstede's six cultural dimensions, including collectivism, power distance, masculinity, uncertainty avoidance, long-term orientation, and

13) https://ec.europa.eu/info/business-economy-euro/euro-area/enlargement-euro-area/convergence-criteria-joining_en

14) https://ec.europa.eu/info/business-economy-euro/economic-and-fiscal-policy-coordination/eu-economic-governancemonitoring-prevention-correction/stability-and-growth-pact_en 
indulgence.15) Finally, local language is vital to banks' operations for their domestic clientele as it is the primary means of communication for banking operations. Langauge ${ }_{i, j, t}$ captures the language commonality between country $y_{i}$ and country $y_{j}$. Table 2 presents the detailed descriptions of the variables and data sources.

Table 2. Panel regression: Variable definitions

\begin{tabular}{|c|c|}
\hline $\begin{array}{l}\text { Name of the variables (proxy) } \\
\text { Dependent variable: }\end{array}$ & Definition \\
\hline conditional comelation $\left(\rho_{i, j, t, c}\right)$ & $\begin{array}{l}\text { Conditional correlation }\left(d c c_{i j}\right) \text { between country } y_{i} \text { and country is calculated using Copula } \\
\text { DCC-GARCH model. The estimated correlation is then Fischer transformed to get } \\
\text { unbounded correlation series as: } \rho_{i, j, t, c}=(1 / 2)\left[\ln \left(1+d c c_{i, j, t, c}\right) /\left(1-d c c_{i, j, t, c}\right)\right] \text {. } \\
\text { Related References: Vo and Daly }(2007) \\
\text { Data Sources: Eurostat }\end{array}$ \\
\hline Independent variables & \\
\hline
\end{tabular}

Panel A: Macroeconomic variables

GDP growth (dGDP)

Absolute difference between the quarterly growth rate of real GDP between country

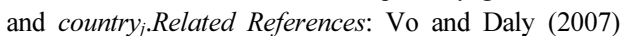

Data Sources: OECD

Inflation (dInf)

Absolute difference in inflation between country $_{i}$ and country $y_{j}$. The quarterly inflation is calculated from data on Eurostat's Harmonized Index of Consumer Prices (HICP). Related References: Kim et al. (2005), Piljak (2013), Mobarek et al. (2016)

Data Sources: Eurostat

Public Debt to GDP (dPDebt) Absolute difference in quarterly government consolidated gross debt as a percentage of Gross Domestic Product (GDP). Government debt as defined in the Mastricht Treaty.Related References: Mayordomo et al. (2015)

Data Sources: Eurostat

Budgetary Balance to GDP (dBudget)

TARGET2 Balance to GDP

Financial Stress Index (dFinStress) Absolute difference in the quarterly value of the Financial Stress Index (ECB's CLIFS) between country $_{i}$ and country $y_{j}$. The CLIFS includes six, mainly market-based, financial stress measures (Duprey, T., and Klaus, B., "Dating systemic financial stress episodes in the EU countries," Working Paper Series, No 1873, ECB, December 2015)

Data Source: ECB

Panel B: Cross-bonder linkages variables

Bilateral Trade Intensity

Bilateral trade intensity calculated as: $T_{i j}, t=(1 / 2)\left[\left(x_{i j, t} / X_{i, t}\right) /\left(x_{w j, t} / X_{w, t}\right)+\left(x_{j i, t} / X_{j, t}\right)\right.$ $\left./\left(x_{w i, t} / X_{w, t}\right)\right]$, where $x_{i j}$ and $x_{w j}$ are the values of country $i$ 's exports and of world exports to country $j$ and where $X_{i t}$ and $X_{w t}$ are country $i$ 's total exports and total world exports, respectively. Related References: Clark and van Wincoop (2001), Narayan et al. (2014) Data Sources: International Monetary Fund's Direction of Trade (DOT), Quarterly

15) For more details, see https://geerthofstede.com/culture-geert-hofstede-gert-jan-hofstede/6d-model-of-national-culture/ 
Table 2. Continued

\begin{tabular}{ll}
\hline Name of the variables (proxy) & Definition \\
\hline $\begin{array}{l}\text { Business Cycle Synchronization } \\
\text { (BCS) }\end{array}$ & The time-varying output correlation index provided by Cerqueira (2013) is calculated \\
& as: $\rho_{i j, t}=1-\frac{1}{2}\left(\frac{d_{j, t}-\bar{d}_{j}}{\left.\sqrt{\frac{1}{T} \sum_{t=1}^{T}\left(d_{j, t}-\bar{d}_{j}\right)^{2}}-\frac{d_{i, t}-\bar{d}_{i}}{\sqrt{\frac{1}{T}} \sum_{t=1}^{T}\left(d_{i, t}-\bar{d}_{i}\right)^{2}}\right)^{2} \text { where } d_{i, t} \text { is the cyclical }}\right.$ \\
& component extracted from real GDP data for each country by applying the \\
& Hodrick-Prescott (HP) filter (Hodrick and Prescott 1997). This is then transformed \\
& to get the unbounded index of business cycle synchronization: $B C S_{i j, t}=\frac{1}{2} \ln \left(\frac{1+\frac{\rho_{i j, t}}{2 T-3}}{1-\rho_{i j, t}}\right)$ \\
& Related References: Buttner and Hayo (2011), Belke (2017) \\
& Data Sources: OECD and Eurostat
\end{tabular}

Panel C: Banking sector variables

Banking Sector Riskiness

Banking Sector Development

Supervisory Independence
Absolute difference between quarterly credit-to-GDP gap between country $y_{i}$ and country $_{j}$ at time $t$. Credit-to-GDP gap measures the risk associated with the credit given to household and businesses in a country. High credit-to-GDP gap indicates a build-up of vulnerabilities in the banking system.

Related references: Borio and Lowe (2002)

Data Sources: Bank of International Settlement (BIS)

Absolute difference between the quarterly private credit-to-GDP ratio between country and country $_{j}$ at time $t$.

Data Sources: Bank of International Settlement (BIS)

Absolute difference in the scores on Independence of Supervisory Authority (Overall) Index developed by Barth et al. (2013). The database by Barth et al. (2013) was built over four surveys. We follow Weiß et al. (2014) and use the index values from the second survey (2002) for 2003 2004, from the third survey (2005) for 2005 2010, and from the fourth survey for 2011 2014. From December 2014 quarter, the difference in scores between two countries is considered as zero due to the implementation of the SSM in the region wherein ECB became the single supervisor. Related references: Perez et al. 2005

Data Sources: Barth, Caprio, and Levine (2013) database

\section{Panel D: Sociological variables}

Culture Distance Index

This is the bilateral cultural distance between country-pair $i$ and $j$, calculated as $K S_{i j}$ $=\left[\left(I_{p i}-I_{p j}\right)^{2} / V_{p}\right] / c$, where $I_{c i}$ is the score for the $c$ th cultural dimension of country $i, I_{c j}$ is the score for the $p$ th cultural dimension of country $j$, and $V_{p}$ is the variance in the $p$ th cultural dimensions across all countries in sample. The larger the KS measure, the greater the cultural distance between country $i$ and country $j$. We use Hofstede's scores on the six-factor cultural dimensions. Related references: Mobarek et al. (2016), Lucey and Zhang (2011), Kogut and Singh (1988)

Data source: Geert Hofstede's six dimensions

Language Commonality

A dummy variable for capturing information on a common language wherein a country gets a score of one if more than $80 \%$ of the country's population has knowledge of English or French or German, otherwise it gets a score of zero. (Of the 24 official languages in the European Union, English, French, and German are the "procedural" languages of the European Commission.)

Data Source: Eurobarometer (2012).

\section{B. Panel data results}

The baseline specification is given by Equation (10). The dependent variable is Fisher-transformed 
quarterly correlation coefficient, estimated in Section 3 using the Copula ADCC GARCH model. The baseline model (Eq. (10)) for all country pairs is estimated. However, because aggregating all country pairs might fail to reveal important coefficient heterogeneities, additional specifications are also measured for core-only country pairs, periphery-only counties pairs, and mixed country pairs. This country-group-wise splitting also captures a different level of interest rate correlations, as observed in Figure 1. All of these estimations contain time-fixed effects and use robust standard errors. The diagnostic tests revealed the presence of heteroskedasticity, serial correlation, and cross-sectional correlation 16 ) (Table 3). Robust estimators of the coefficients' covariance matrix are estimated with errors clustering both cross-sectional and along the time dimension. To this end, a White's heteroskedasticity and autocorrelation consistent covariance matrix of coefficients was estimated using Arellano's (1987) method, which allows a fully general structure with respect to serial correlation and heteroskedasticity and is suitable in case of fixed effects (Stock and Watson 2006). The standard errors thus estimated are robust to heteroskedasticity, cross-section correlation, and serial correlation in the errors.

Tables 4 to 9 present the results for different interest rate categories. The results presented in every table follow the same sequence of specifications: (I) the baseline specification of Eq. (10) estimated for all country pairs; (II) Eq. (10) estimated for core-only country pairs; (III) Eq. (10) estimated for periphery-only country pairs; (IV) Eq. (10) estimated for mixed (core-periphery) country pairs. Each of these specifications contains time-fixed effects. In specifications (V), (VI), (VII), (VIII), and (IX), the role of the GFC, EDC, SSM, SRM, and UMP of negative policy rates in the euro area is examined. These are captured through five separate dummy variables, taking a value of 1 for periods of the GFC (2007Q3 2009Q3), EDC (2009Q4 2013Q4), SSM (2014Q4 2018Q3), SRM (2016Q1 2018Q3), and UMP (2014Q2 2018Q3), respectively. Given that these five dummy variables are common to all country pairs, these are introduced in the specifications one at a time. In addition, time-fixed effects are omitted in these model specifications.

Table 4 presents the regression results for short-term deposits (STDs) interest rate correlation. Starting with the first column, it can be seen that interest rate correlations seem to be determined by the differentials of all macroeconomic regressors except inflation and the differential of TARGET2 balance. The coefficients of the differential in macroeconomic variables are negative (significant). This finding indicates that a lower differential in macroeconomic fundamentals increases the interest rate comovement. These results are consistent with those of Sehgal et al. (2018), Mobarek et al. (2016), and Bracker and Koch (1999), who report that similar macroeconomic fundamentals enable greater financial convergence. Further, the coefficient for language commonality is found to be positive (significant) and confirms the theory that differences

16) We tested for cross-sectional dependence/contemporaneous correlations using the Breusch-Pagan LM test of independence and the Pasaran CD test, the Breusch-Godfrey/Wooldridge test for serial correlation using, and we tested for heteroskedasticity using the Breusch-Pagan test. 
Table 3. Diagnostic tests*

\begin{tabular}{|c|c|c|c|c|c|c|c|c|c|c|c|}
\hline Type & & Diagnostic Tests \# & & & & Model & Speci & ations & & & \\
\hline & $\begin{array}{l}\text { Unit } \\
\text { Root }\end{array}$ & Other Tests & (I) & (II) & (III) & (IV) & (V) & (VI) & (VII) & (VIII) & (IX) \\
\hline \multirow[t]{4}{*}{ STD } & $-12.77^{*}$ & Breusch-Pagan LM Test & $4835.10^{*}$ & $318.33^{*}$ & $151.35^{*}$ & $1624.90^{*}$ & $12052^{*}$ & $14332 *$ & $16586^{*}$ & $16680^{*}$ & $16451^{*}$ \\
\hline & & Person CD Test & $-5.40^{*}$ & $-5.71^{*}$ & $-5.82^{*}$ & $-5.46^{*}$ & $97.27^{*}$ & $106.23 *$ & $116.05^{*}$ & $116.66^{*}$ & $115.59^{*}$ \\
\hline & & Breusch-Godfrey/Wooldridge Test & $2650.50^{*}$ & $595.01^{*}$ & $363.63^{*}$ & $1490.5^{*}$ & $1702.8^{*}$ & $1926.7^{*}$ & $1960.4^{*}$ & $1969.8^{*}$ & $1951.8^{*}$ \\
\hline & & Breusch-Pagan Test & $219.95^{*}$ & $41.35^{*}$ & $53.16^{*}$ & $243.13^{*}$ & $216.14^{*}$ & $190.64 *$ & $187.58^{*}$ & $185.51^{*}$ & $183.19^{*}$ \\
\hline \multirow[t]{4}{*}{ MTD } & $-8.04 *$ & Breusch-Pagan LM Test & $2083.90^{*}$ & $319.08^{*}$ & $88.64 *$ & $501.58^{*}$ & $2200.3^{*}$ & $2309.9^{*}$ & $2427.6^{*}$ & $2429.4^{*}$ & $2427.8^{*}$ \\
\hline & & Person CD Test & $-5.43^{*}$ & $-5.47 *$ & $-6.1^{*}$ & $-5.65^{*}$ & $27.37^{*}$ & $28.67^{*}$ & $31.85^{*}$ & $31.56^{*}$ & $31.88^{*}$ \\
\hline & & Breusch-Godfrey/Wooldridge Test & $1947.70^{*}$ & $457.28^{*}$ & $233.73^{*}$ & $1005^{*}$ & $881.18^{*}$ & $896.86^{*}$ & $910.99^{*}$ & $908.63^{*}$ & $911.94 *$ \\
\hline & & Breusch-Pagan Test & $252.23^{*}$ & $48.14^{*}$ & $31.57^{*}$ & $66.46^{*}$ & $103.75^{*}$ & $90.39 *$ & $102^{*}$ & $93.84 *$ & $102.13^{*}$ \\
\hline \multirow[t]{4}{*}{ STL } & $-4.58^{*}$ & Breusch-Pagan LM Test & $5837.50^{*}$ & $443.86^{*}$ & $273.52^{*}$ & $2159.5^{*}$ & $4601.7^{*}$ & $4595.3^{*}$ & $4654.7^{*}$ & $4620^{*}$ & $4678.2^{*}$ \\
\hline & & Person CD Test & $-4.83^{*}$ & $-5.65^{*}$ & $-5.83^{*}$ & $-5.23^{*}$ & $40.32^{*}$ & $39.07^{*}$ & $39.7^{*}$ & $38.75^{*}$ & $39.77^{*}$ \\
\hline & & Breusch-Godfrey/Wooldridge Test & $2681.40^{*}$ & $578.41^{*}$ & $544.45^{*}$ & $1456.7^{*}$ & $246.97 *$ & $243.38^{*}$ & $245.68^{*}$ & $249.13^{*}$ & $247.98^{*}$ \\
\hline & & Breusch-Pagan Test & $735.00^{*}$ & $56.87^{*}$ & $285.13^{*}$ & $206.93^{*}$ & $314.79^{*}$ & $325.41^{*}$ & $318.94^{*}$ & $311.86^{*}$ & $316.26^{*}$ \\
\hline \multirow[t]{4}{*}{ MTL } & $-4.76^{*}$ & Breusch-Pagan LM Test & $5354.10^{*}$ & $511.58^{*}$ & $238.34^{*}$ & $1254.6^{*}$ & $3440.4^{*}$ & $3393.4^{*}$ & $3442.3^{*}$ & $3470.1^{*}$ & $3457.4^{*}$ \\
\hline & & Person CD Test & $-2.85^{*}$ & $-5.69^{*}$ & $-5.81^{*}$ & $-5.2^{*}$ & $7.68^{*}$ & $7.69^{*}$ & $7.78^{*}$ & $8.18^{*}$ & $8.11^{*}$ \\
\hline & & Breusch-Godfrey/Wooldridge Test & $2708.20^{*}$ & $585.56^{*}$ & $539.66^{*}$ & $1482.9^{*}$ & $674.45^{*}$ & $669.53^{*}$ & $678.61^{*}$ & $681.64^{*}$ & $680.45^{*}$ \\
\hline & & Breusch-Pagan Test & $248.04^{*}$ & $97.79^{*}$ & $178.77^{*}$ & $191.1^{*}$ & $141.56^{*}$ & $136.5^{*}$ & $143.48^{*}$ & $138.66^{*}$ & $143.95^{*}$ \\
\hline \multirow[t]{4}{*}{ STM } & $-8.23 *$ & Breusch-Pagan LM Test & $3511.20^{*}$ & $442.06^{*}$ & $198.65^{*}$ & $1172.4^{*}$ & $4968^{*}$ & $5181.8^{*}$ & $5297.3^{*}$ & $5295.6^{*}$ & $5252.1 *$ \\
\hline & & Person CD Test & $-5.59^{*}$ & $-5.75^{*}$ & $-5.89^{*}$ & $-5.64 *$ & $47.67^{*}$ & $50.2^{*}$ & $51.2^{*}$ & $51.19^{*}$ & $50.48^{*}$ \\
\hline & & Breusch-Godfrey/Wooldridge Test & $2757.60^{*}$ & $497.99^{*}$ & $468.68^{*}$ & $1450.1^{*}$ & $257.69^{*}$ & $284.09^{*}$ & $288.09^{*}$ & $289.59^{*}$ & $285.96^{*}$ \\
\hline & & Breusch-Pagan Test & $131.49^{*}$ & $102.64^{*}$ & $58.7^{*}$ & $152.87^{*}$ & $55.07^{*}$ & $56.48^{*}$ & $58.56^{*}$ & $54.7^{*}$ & $57.83^{*}$ \\
\hline \multirow[t]{4}{*}{ MTM } & $-6.92 *$ & Breusch-Pagan LM Test & $2203.10^{*}$ & $572.62^{*}$ & $50.1^{*}$ & $534.36^{*}$ & $2607.8^{*}$ & $2577.7^{*}$ & $2619.7^{*}$ & $2620.6^{*}$ & $2620.7^{*}$ \\
\hline & & Person CD Test & $-5.34 *$ & $-5.31^{*}$ & $-6.74^{*}$ & $-5.67^{*}$ & $38.03^{*}$ & $37.45^{*}$ & $38.19^{*}$ & $38.16^{*}$ & $38.2^{*}$ \\
\hline & & Breusch-Godfrey/Wooldridge Test & $1816.50^{*}$ & $774.55^{*}$ & $99.31^{*}$ & $813.83^{*}$ & $208.55^{*}$ & $203.11^{*}$ & $208.63^{*}$ & $209.33^{*}$ & $208.83 *$ \\
\hline & & Breusch-Pagan Test & $257.09^{*}$ & $94.64^{*}$ & $29.9^{*}$ & $37.52 *$ & $221.51^{*}$ & $220.47^{*}$ & $208.2^{*}$ & $210.03 *$ & $206.49 *$ \\
\hline
\end{tabular}

\# Breusch-Pagan LM test of independence and Pasaran CD test are used to test cross-sectional dependence/contemporaneous correlation, Breusch-Godfrey/Wooldridge test is employed for serial correlation using and Breusch-Pagan test for heteroskedasticity.

* significant at $1 \%$ level

in language act as a natural barrier to retail banking integration across borders. Further, observing specifications (II), (III), and (IV) jointly, the regression results show that coefficient heterogeneity exists across these three specifications. For periphery-only country pairs, only the sociological variables of language commonality and cultural distance are significant determinants of correlation. However, in the case of core-only country pairs and mixed-country pairs, the differential in macroeconomic fundamentals and banking characteristics is significant. Notably, the banking risk differential is positively significant for these groups. This result can be interpreted in terms of flight-to-quality dynamics and risk diversification, wherein banks diversify their exposure in other core countries in the region. Further, we investigate the role of the GFC, EDC, SSM, SRM, and UNP in specifications (V) to (IX) through dummy variables. All these dummy 


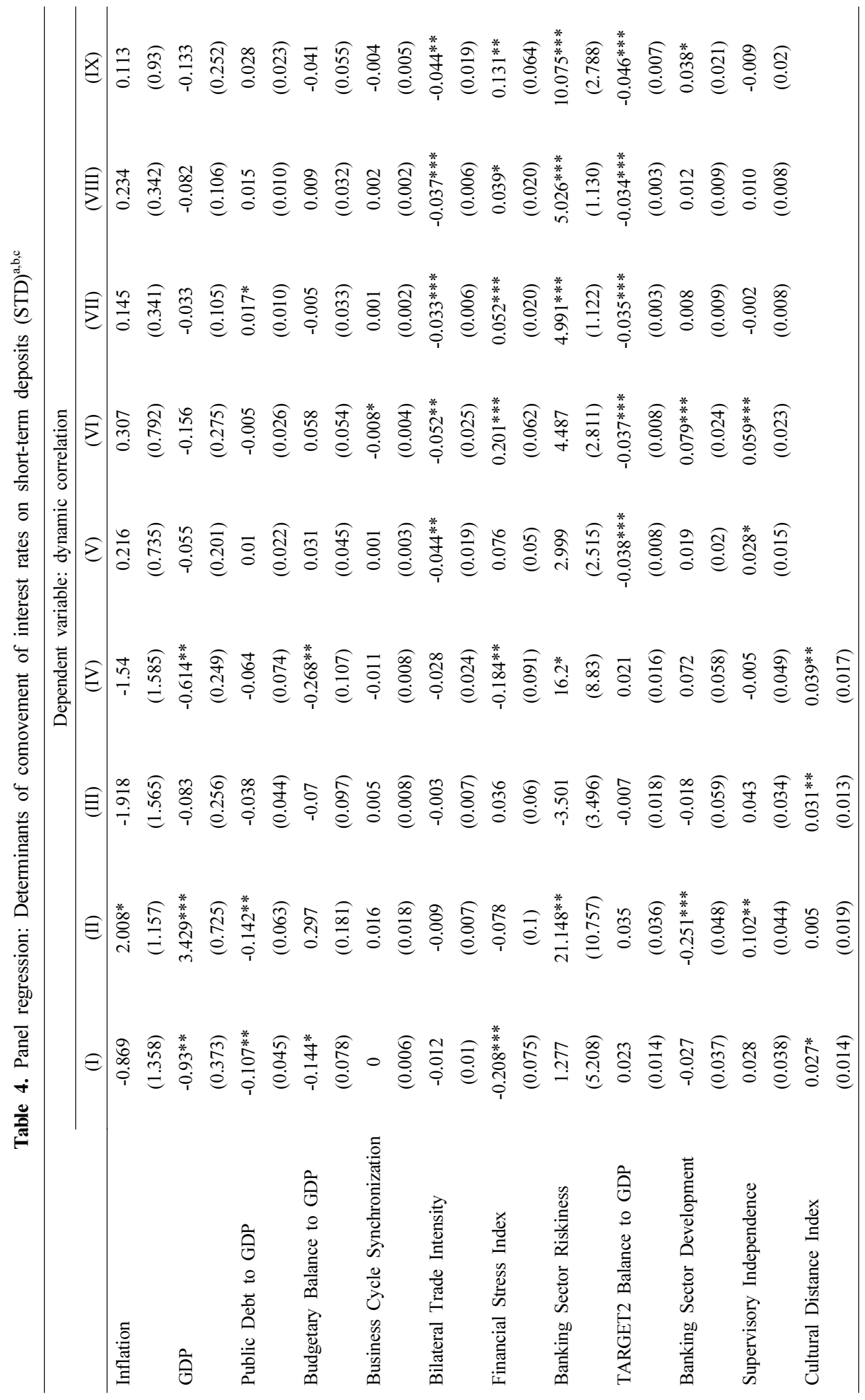




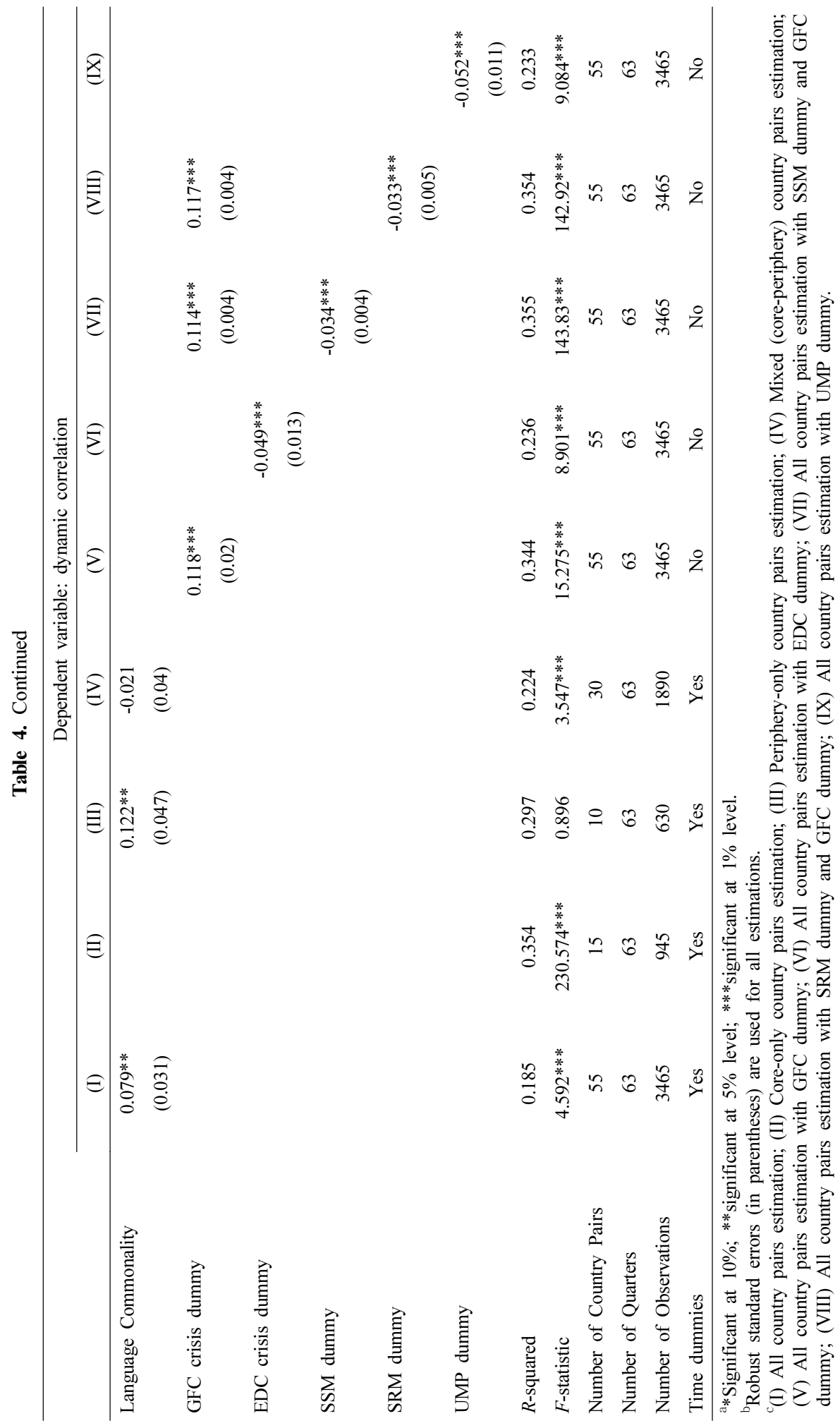


variables are statistically significant. The coefficient of the GFC carries a positive sign pointing toward the possibility of a joint reaction to the subprime crisis. However, the EDC carries the expected negative sign, as it is associated with lower interest rate correlation. The SSM and SRM are associated with lower correlation. This finding is confounding as these policy mechanisms were expected to gradually lead toward banking union. Similarly, the introduction of the UMP (negative interest rates) is also associated with lower correlation. This may be attributed to heterogeneity in the transmission of policy rates to short-term deposit rates in different countries.

Table 5 reports the results for medium-term deposit (MTD) interest rates. The interest rate correlations in MTDs are lower than those in STDs (Figure 1). The first column of the table shows that unlike the case of STD interest rates, the correlations in MTD interest rates are not determined by the differential in macroeconomic variables. However, the differential in financial stress and banking risk is negatively significant, and the TARGET2 ratio is positively significant. The coefficient heterogeneity across specifications (III) to (V) is interesting. While a higher public debt differential, a higher TARGET2 ratio differential, and larger cultural distance dampen interest rate correlations among periphery-only country pairs, they are associated with higher correlations in core groups. Here as well, as in the case of STD interest rate correlation, for the core-only group, a higher differential in banking variables between two countries is associated with higher comovement. This can be attributed to the flight-to-quality and diversification of the banking sector's exposure across other core countries in the region. For both core and periphery groups, bilateral trade intensity is a significant and positive determinant of correlation. On the other hand, the financial stress differential, which is insignificant in the case of the core-only group and the mixed group, becomes positively significant in the case of the periphery-only group. This can be due to synchronous periods of financial stress in these counties and the similar state of credit availability and interest rate movements during this period. Similarly, the differential in the supervisor's independence is significant (positive) only in the case of periphery-only country pairs. We interpret this result by considering the persistently subdued correlations in this group during the EDC and post-crisis period even after the implementation of the ECB as a single supervisor under the SSM. Interest rate correlations among mixed-country pairs appear to be determined only by bilateral trade intensity (negative) and common language (negative). This can be interpreted in the light of the bankers' cross-border risk diversification strategies that result in the increase in exposure among mixed-country pairs. Further, we observe that the results for the GFC, EDC, SSM, and SRM dummies are similar to those of the STD estimation; however, the coefficient of the UMP is not statistically significant.

Table 6 presents the results for interest rate correlations in the short-term loans (STLs) category. Baseline estimation (I) shows that only the government's budget differential is a significant regressor. It carries a negative sign, implying that a higher difference in government 


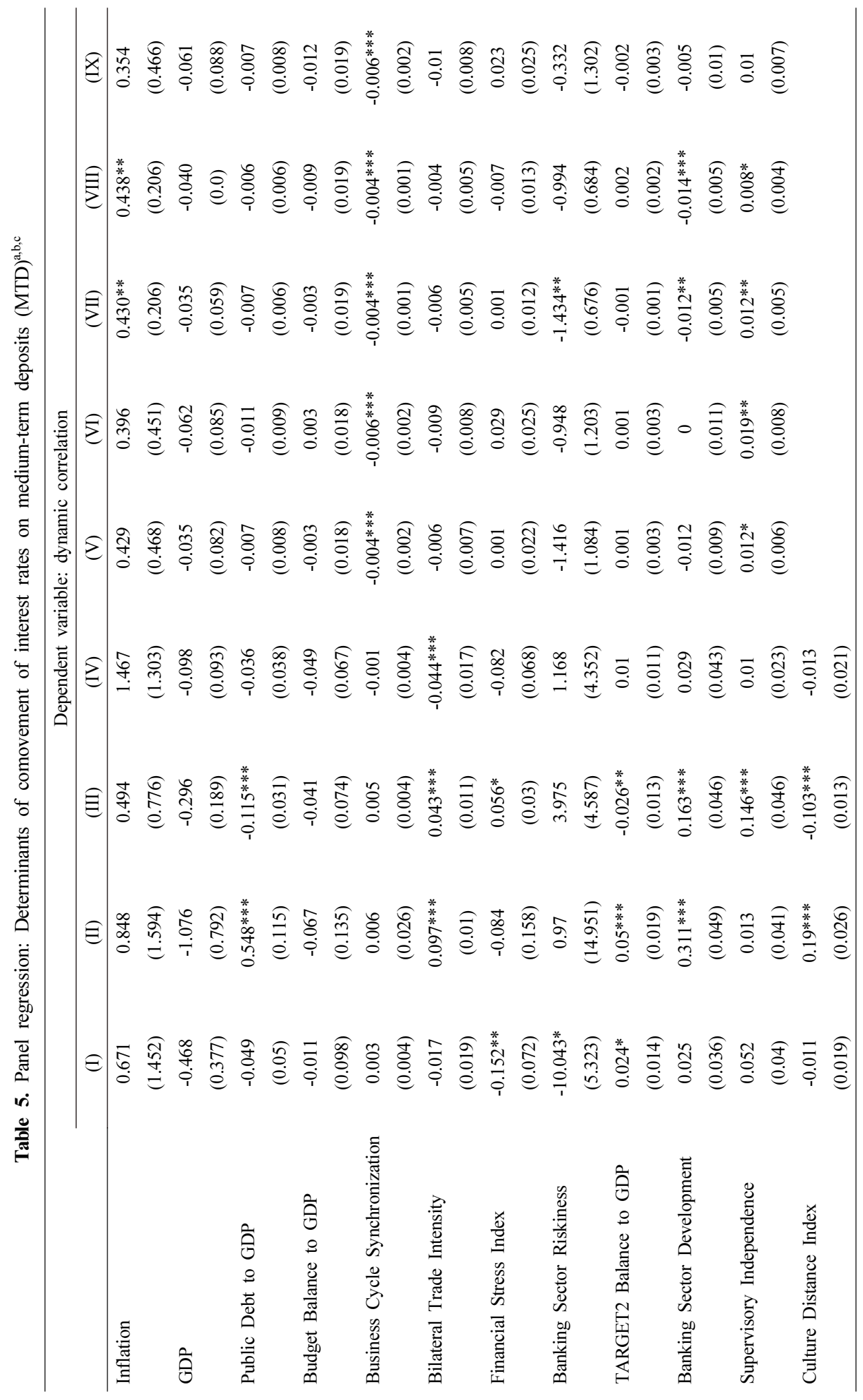




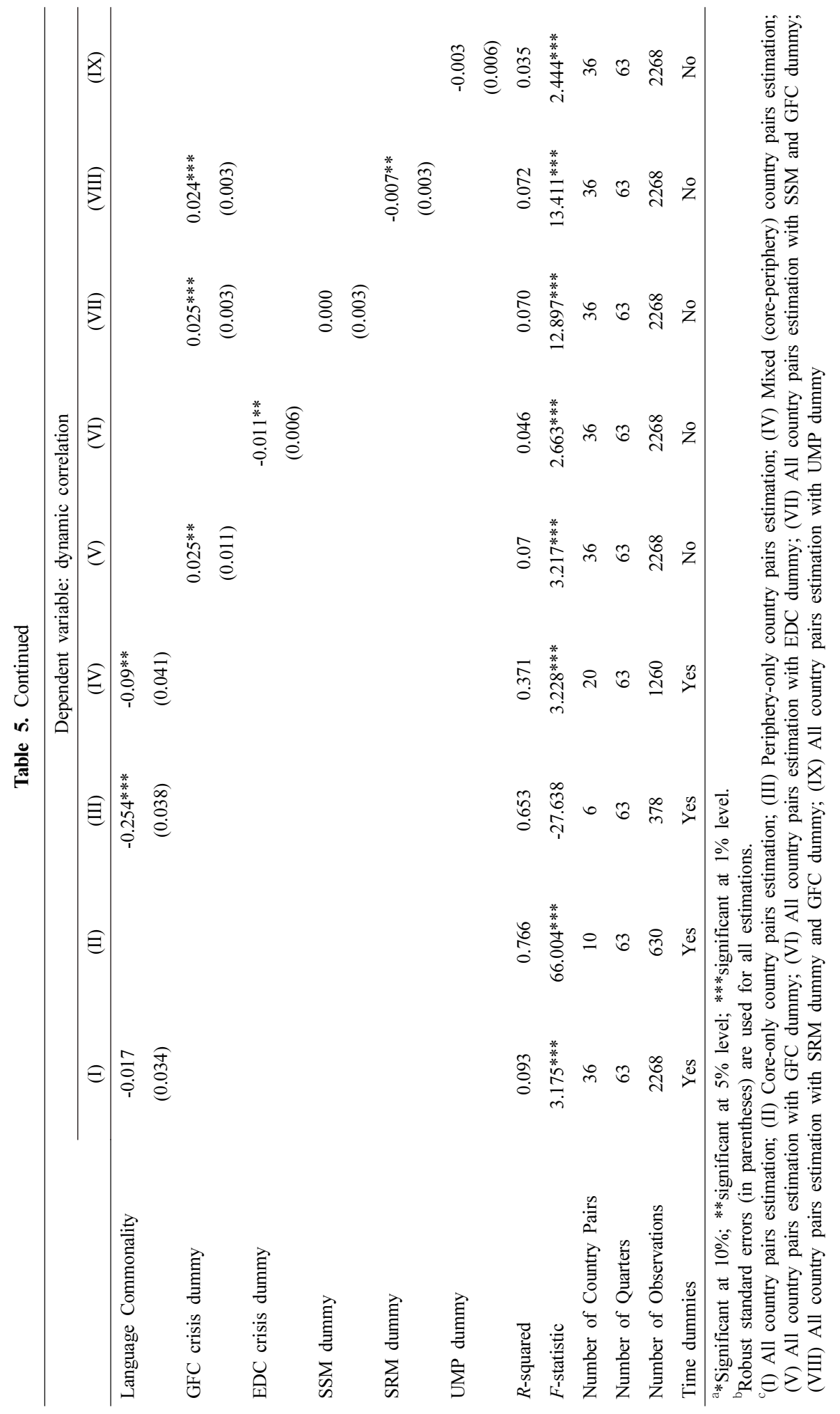




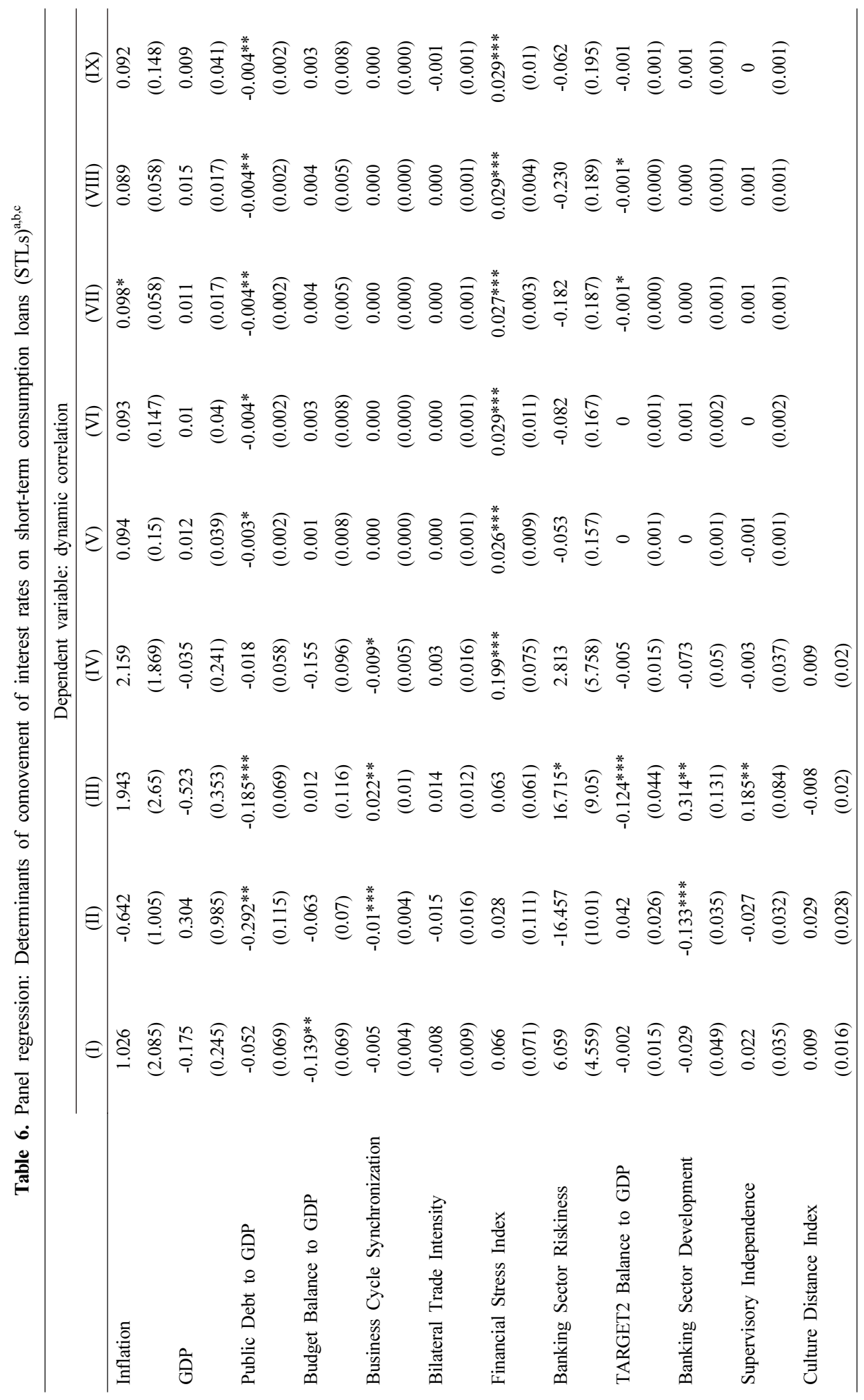




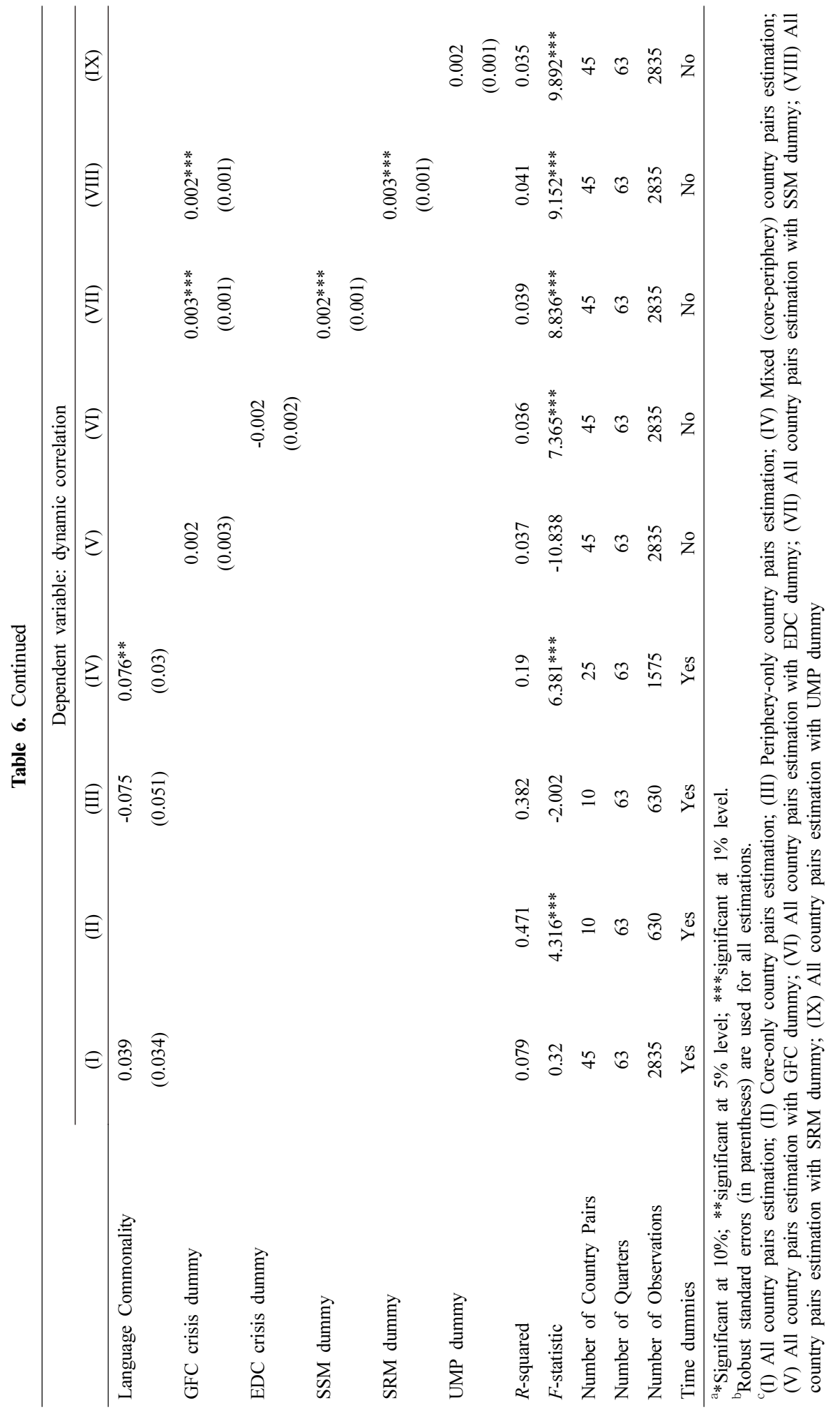


budget balances among countries but lowers correlation as it often leads to heterogeneity in macroeconomic stability and credit availability to the private and household sectors across these countries. Further, in specifications (II to IV), the coefficient estimate for business cycle synchronization is positive and significant in the case of periphery-only country pairs. However, it has a negative impact on correlation in the case of core countries (as seen in estimates for core-only pair and mixed-country pair specifications). This can be attributed to greater access to cross-border credit availability and higher cross-border fund flows between core countries during the periods of heterogeneous business cycle conditions among them. The differential in the public debt ratio is negatively significant for both core and periphery pairs. It is noteworthy that for all characteristics of the banking sector, a higher differential is associated with higher interest rate correlations among periphery-only pairs. This finding is interpreted in view of periphery countries being the destinations of diversification-oriented investment. As differentials in bank characteristics increase among the periphery countries, these countries are viewed as a heterogeneous bundle from the perspective of portfolio diversification and thus receive synchronous cross-border fund flows, leading to a similar level of liquidity and credit availability and thus similar movements of short-term lending rates. We also observe that a common language is a significant (positive) determinant of interest rate correlations only among mixed-country pairs. Further, the SSM and SRM dummies are positive and carry the expected positive sign in case of STL interest rate correlations.

In Table 7, for the medium-term loan (MTL) interest rate correlation, the estimated result for baseline specification shows that only macroeconomic variables of budgetary balance differential and financial stress are significant regressors, and as expected, their coefficients are negative. A comparison between specifications for different country groups (II to IV) reveals coefficient heterogeneity. For instance, for core-only pairs, the differentials in financial stress and bank development are significant (negative) determinants of correlations; however, for the periphery group, these regressors are insignificant. Further, the sociological factor of a common language is a significant (and positive) determinant only in case of the periphery-only group. For mixed-country pairs, only bilateral trade intensity is a significant (positive) determinant of correlation. In specifications (V) to (IX), the GFC and SSM dummies are significant (positive).

Table 8 presents the regression estimations for short-term mortgage (STM) loans. As seen in the first column, the correlations in STM interest rates appear to be determined by only two of the regressors. The budgetary balance differential and the difference in supervisory independence are weakly significant. Results of country-group-wise specifications show that bilateral trade intensity is a significant determinant of STM interest rate correlation. However, it carries opposite signs for these two specifications. Further, a higher inflation differential is observed to decrease the interest rate correlations in core-only country pairs, while it is insignificant for the periphery-only country group. On the other hand, the differential in 


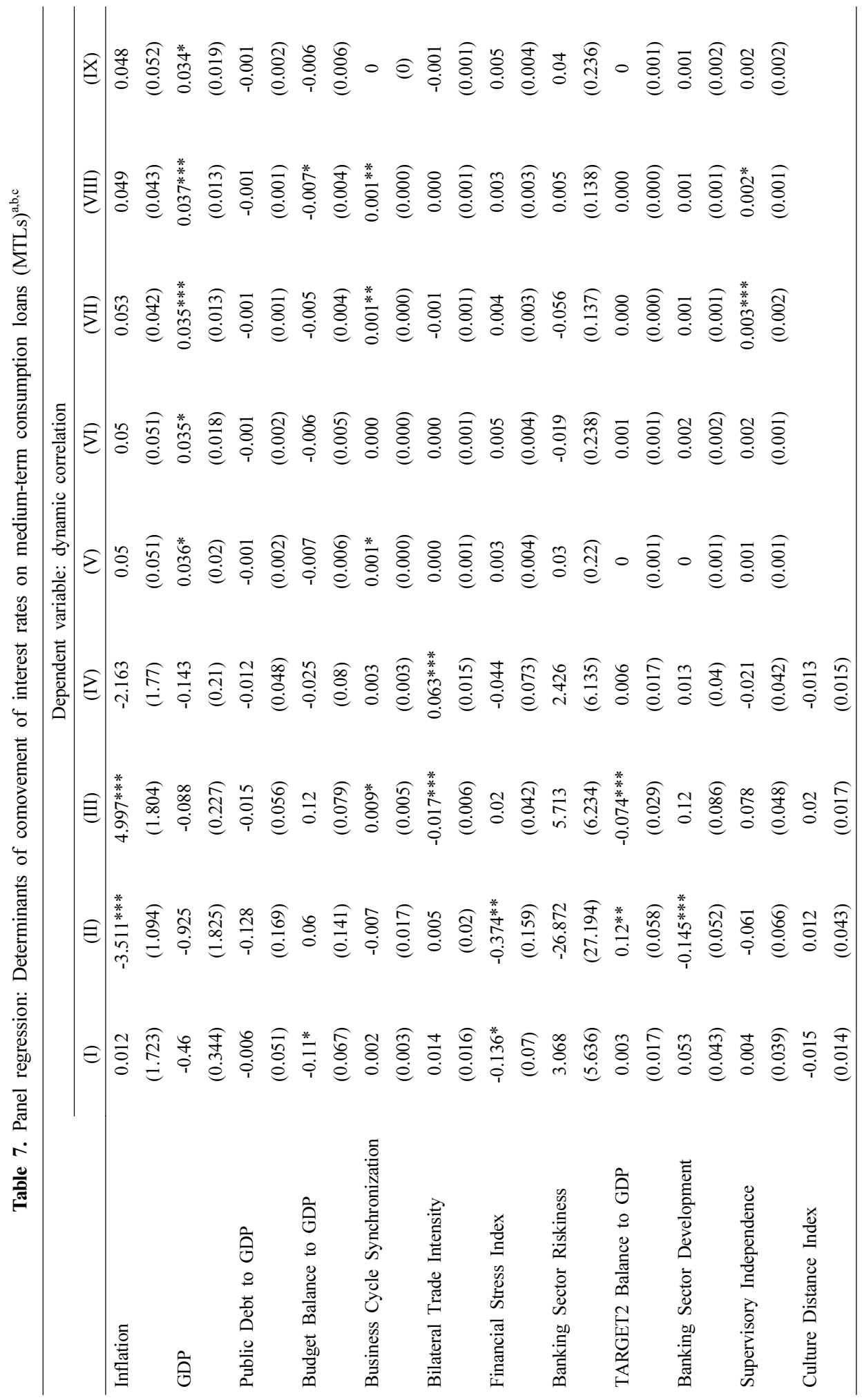




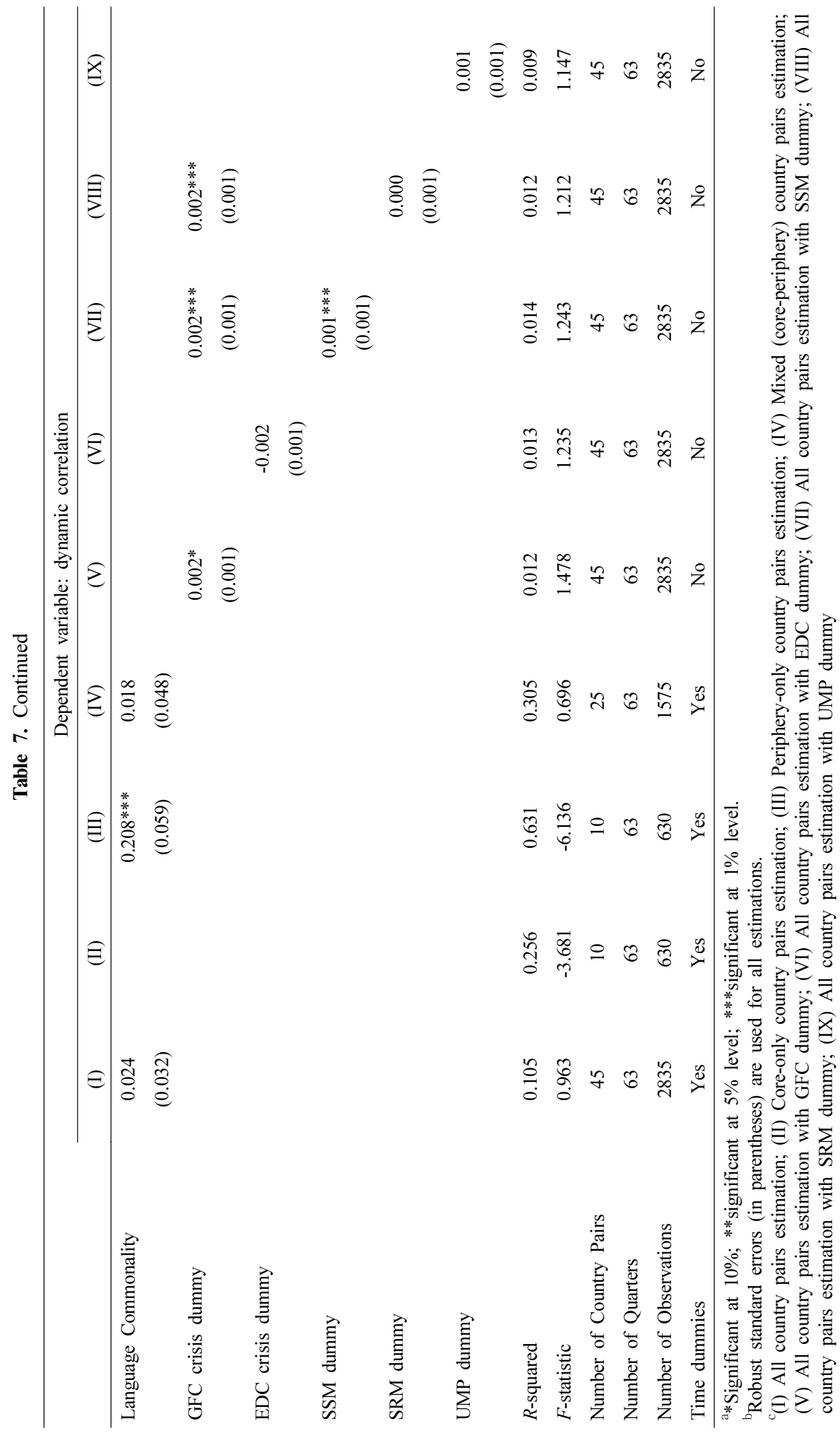


694 Journal of Economic Integration Vol. 34, No. 4

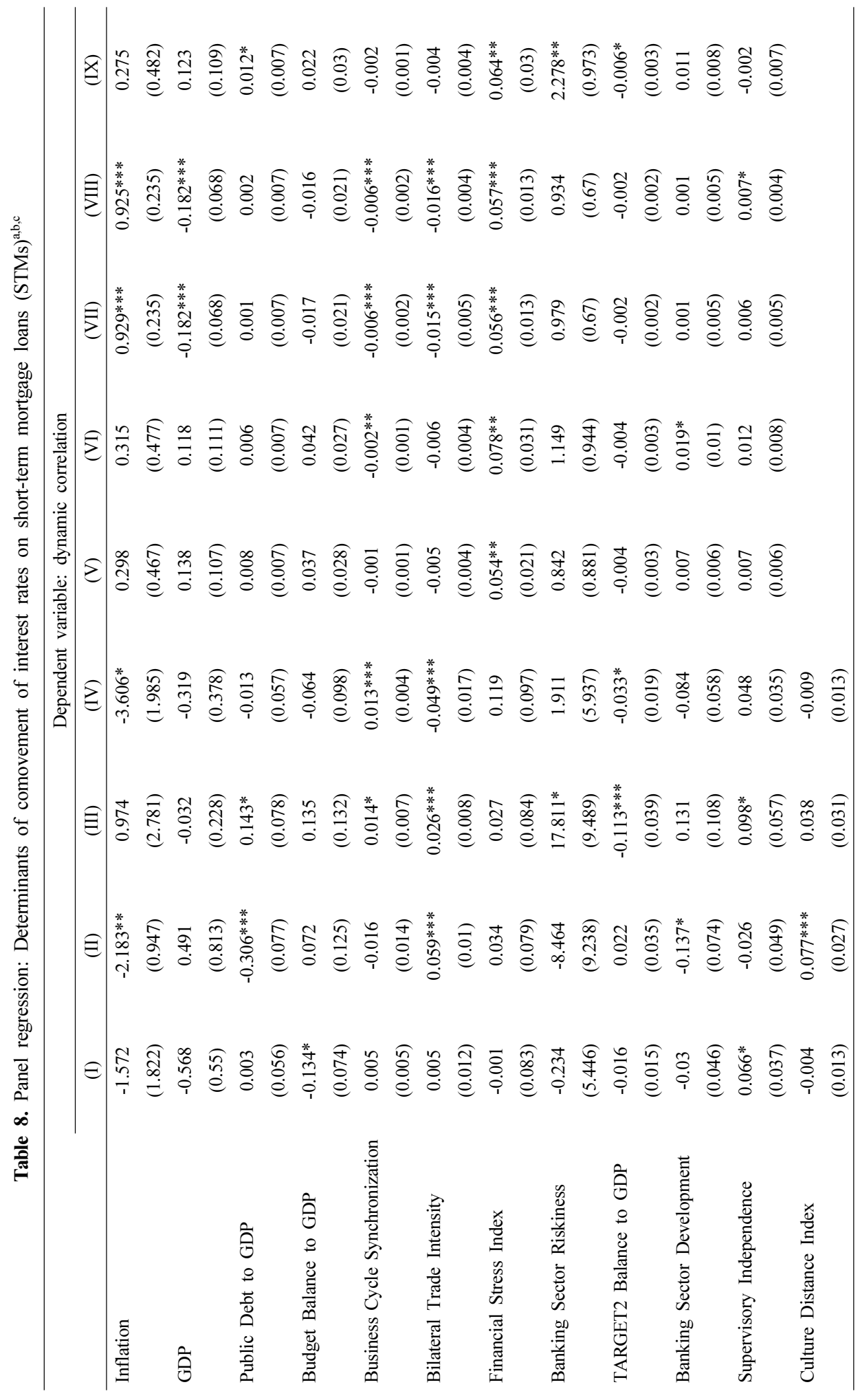




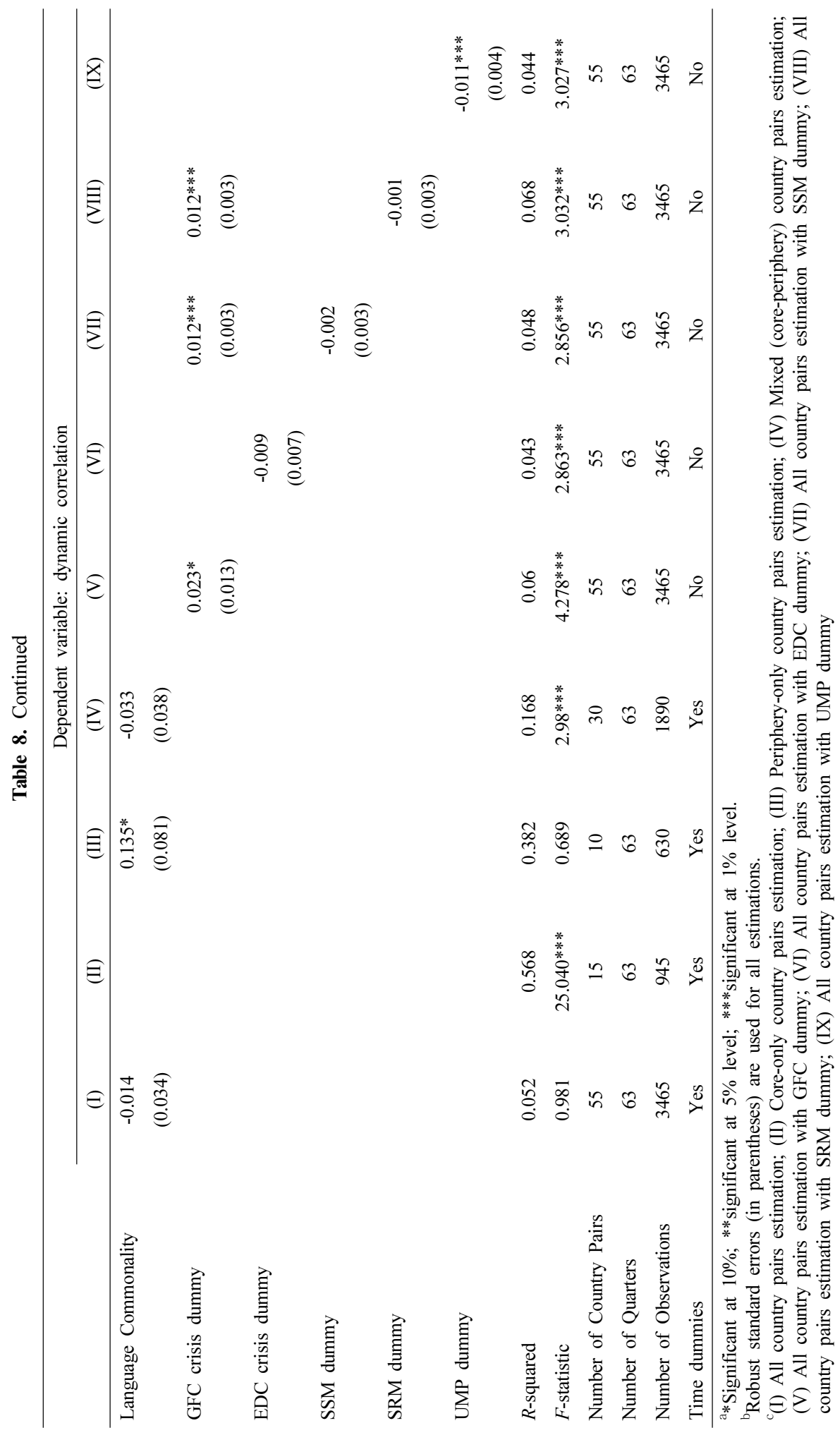


TARGET2 (negatively) and degree of business cycle synchronization (positively) are statistically significant determinants for periphery countries (as seen in the periphery-only specification as well as the mixed-country group). However, these regressors are not significant for core countries. In addition, in what is similar to the observations in the STL category, the differentials in banking risk and supervisory independence are positively significant determinants of STM interest rate correlations among the periphery-only pairs. Language commonality is a significant (and positive) determinant only in the case of the periphery-only country group. In specifications (V to IX), it is observed that while GFC is positive and significant, a result that is similar to those in other interest rate categories, the EDC is not significant. In addition, the UMP of the negative policy rate is significant and is associated with a decrease in interest rate comovement.

Finally, Table 9 presents the results for interest rate correlations for the medium-term mortgage (MTM) category. For this category, the baseline specification shows that only two regressors determine the correlations. While the GDP growth differential is negative and weakly significant, the coefficient of the differential in bank development is positive. Further, in the specifications with respect to country groups, coefficient heterogeneity can be observed, particularly in banking and in sociological variables. The banking-specific variables are significant and positive, in what is similar to the case of interest rate correlations for the STL and STM categories. The sociological variables of cultural distance and common language are significant in the case of the mixed-country pair group.

\section{Conclusion}

The financial turbulence in the global financial landscape and the sovereign debt crisis in the Eurozone in the first decade of the euro invoked doubts regarding the future of the euro (Battistini et al. 2013, Philippas and Siriopoulos 2013). However, the policymakers in the euro area are strongly committed to preserving the euro, as stated in the "Whatever it takes" speech17) by ECB president Mario Draghi, and the multiple policy measures toward banking union to foster a single financial market. Recently, on the 20th anniversary of the euro, Draghi reiterated its importance as the source of price stability and integration in the monetary union, ${ }^{18)}$ while IMF's managing director Christine Lagarde has emphasized the need for a banking union to further strengthen the euro. ${ }^{19)}$ In this context, the present study examines retail banking integration in the euro area using interest rate data for six categories of retail banking products (deposits

17) https://www.ecb.europa.eu/press/key/date/2012/html/sp120726.en.html

18) https://www.ecb.europa.eu/press/key/date/2019/html/ecb.sp190115.en.html

19) Euro 2.0: Past, Present, and Future of Euro Area Integration, (June 25, 2018), https://www.imf.org/en/News/Articles/2018/06/22/sp062518-euro-area-integration 


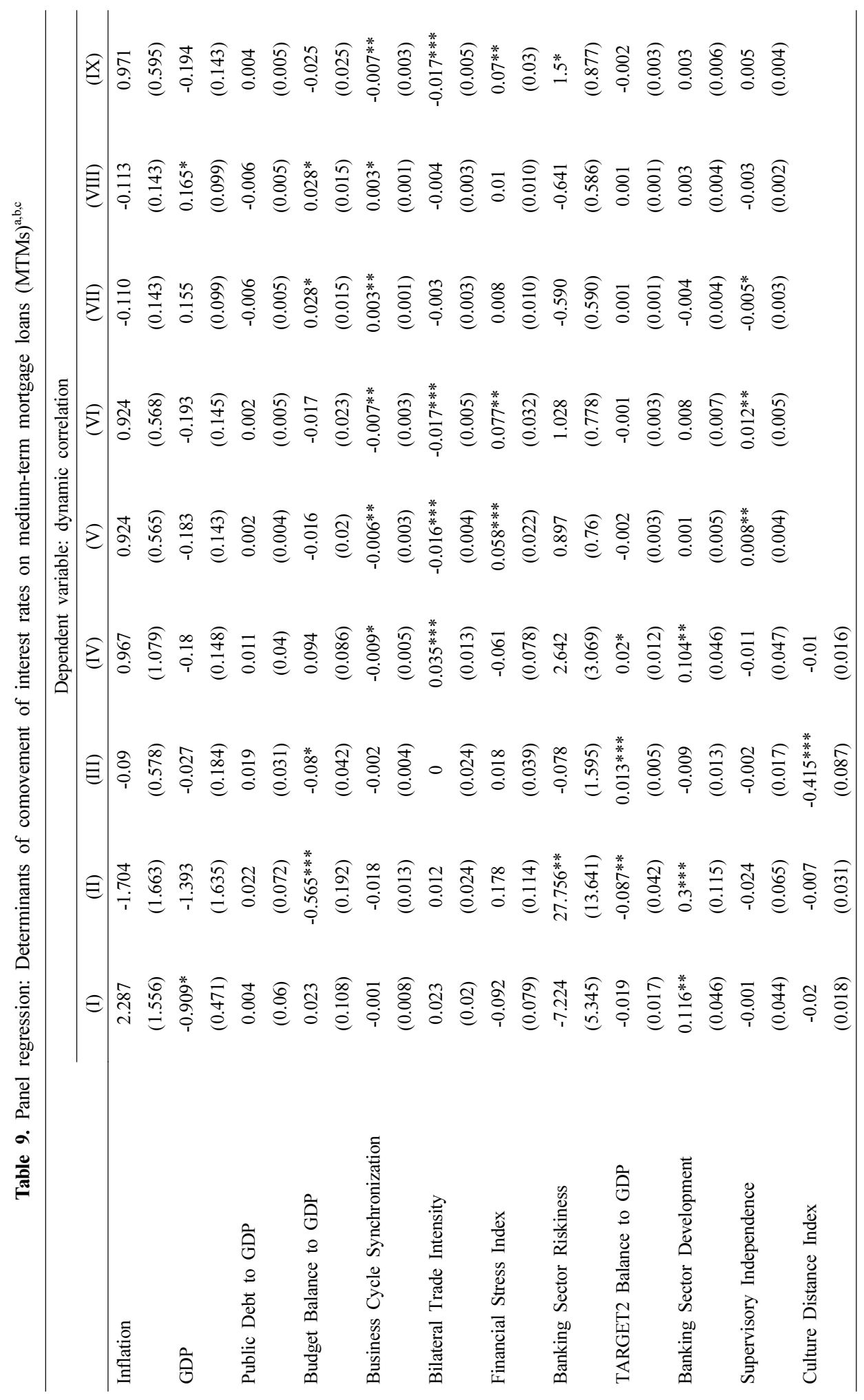




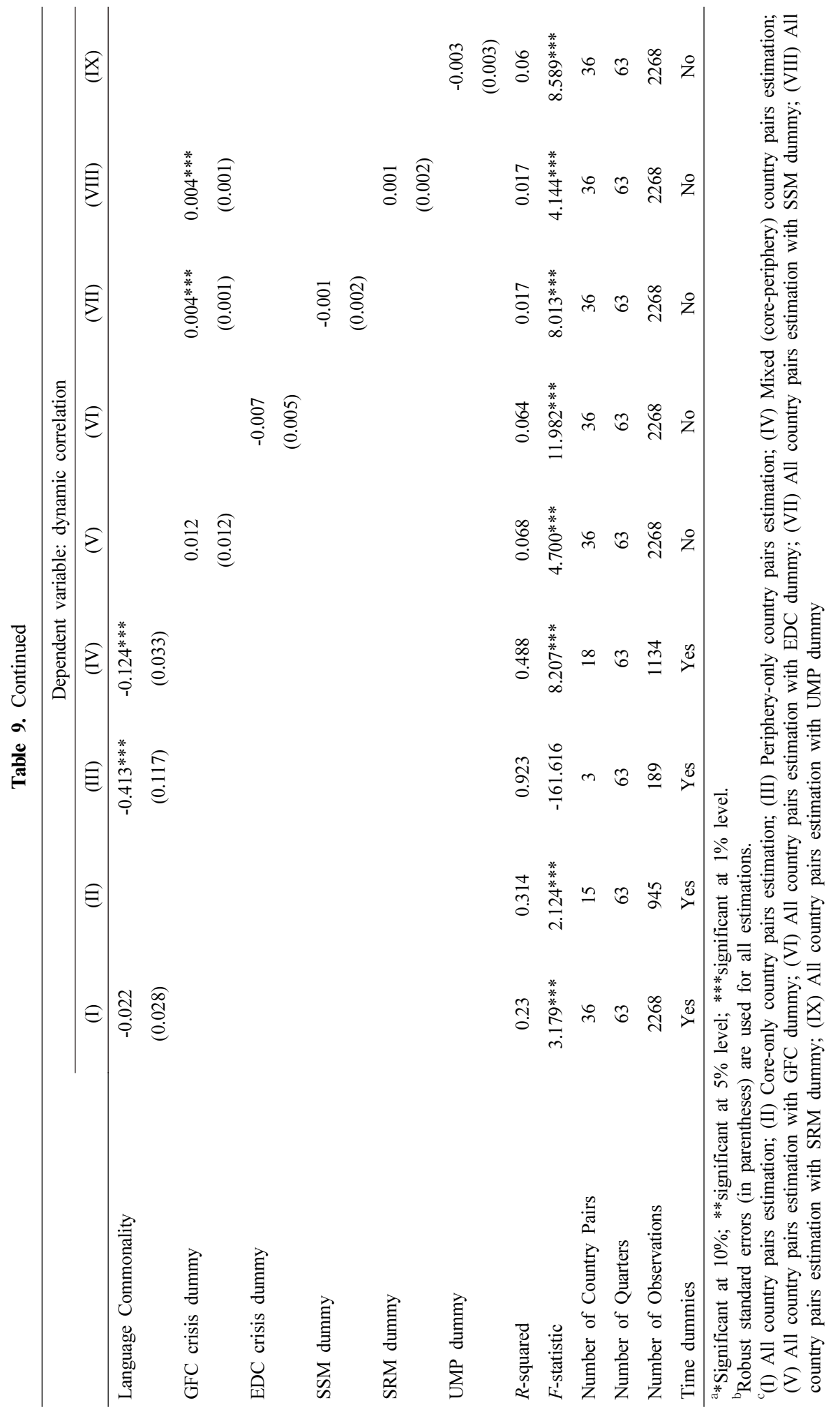


and loans) to households during the crisis and non-crisis periods. We first estimate country pairwise, time-varying interest rate correlations using Copula DCC-GARCH. The study results conclude that retail banking integration is still weak after 20 years of the single currency, monetary union, and greater cross-border flow of funds. The recent policy measures of the SSM and the SRM are yet to stimulate higher interest rate correlations among the euro area countries. The comparison of correlations across product type and between two groups discloses heterogeneity in interest rates between the country groups (core and periphery); between product types (deposit, consumption loan, and mortgage loan); and between maturity type (short-term and medium-term).

Further, cross-country panel regressions are estimated to find the determinants of dynamic interest rate correlations using the differentials in macroeconomic variables, banking sector-specific variables, variables on cross-country linkages, and sociological variables. From the study results, we conclude that differences in fundamental factors play a limited role in determining the degree of retail banking integration in the region. Instead, the weak retail banking integration can be attributed to the intrinsic nature of this sector, including factors such as information asymmetry, which retail banks face as they expand their operations across the border on the basis of clients' creditworthiness, local cultural norms related to lending and borrowing, and governmental intervention in the banking sector because of its social importance. We also observe heterogeneity in the significance of determinants. The variables appear to determine deposit rate correlations more than they determine interest rate correlations on the lending products. Further, the differential in the banking characteristics of risk, development, and supervisory independence is positively related to higher correlations in short-term credit products (consumption loans and mortgages). In addition, comparison across country group-specific estimations also reveals considerable coefficient heterogeneity. For instance, the banking variables of bank risk, bank development, and supervisory independence variables are significant, particularly in the case of core economies. Similarly, the differential in TARGET2 balances and language commonality are significant determinants among periphery-only pairs.

In general, the macroeconomic variables of budgetary balance and financial stress differentials are important determinants, while cross-linkage variables of BCS and bilateral trade intensity are not key factors for most of the specifications. Further, the EDC has a weaker (negative) impact than the GFC, which is positively associated with interest rate correlations across all categories. The policy mechanisms of dummies for the SSM and the SRM are observed to have a mixed impact on interest rate correlations across different types of banking products as their dummies are negatively significant in the case of deposits, positively significant in the case of consumption loans, and not significant in the case of mortgage loans. The dummy variable for the UMP bears a negative sign, suggesting dissimilar monetary policy transmission across the member countries. 
The study findings advance the literature on the important topic of financial integration, particularly the less-investigated retail banking integration in the euro area. A strong retail banking integration has a two-way effect: it eases cross-border financial transactions. The resulting easy availability of credit has the potential to create an environment of excessive leverage. However, in general, it is preferable as it enables efficiency through competition, increased in financial inclusion, and social welfare through gradual convergence toward the highest prevailing interest rates on deposits and the lowest prevailing rates on loans in the region. For a more integrated banking system and ultimately the achievement of the banking union in the euro area, the respective national governments should endeavor to create a level playing field for foreign banks. This includes disregarding their tendency toward protectionism; enabling improved sharing of information on consumers' creditworthiness; and harmonizing taxation laws, both concerning the tax treatment of banking products, as well as corporate tax, faced by banks.

Although the present study covered only the oldest members of the euro area, the results have implications for other existing and future member countries; it also evaluates the role of fundamentals on the level of retail banking correlation. Future research in this direction could focus on an expanded set of countries, including new euro area members and countries that are likely to join the euro area in near future as they undergo the process of economic reforms to join the monetary union.

\section{References}

Ahlborn, M., and Wortmann, M. (2018). "The core-periphery pattern of European business cycles: A fuzzy clustering approach.” Journal of Macroeconomics, 55, 12-27.

Anastasiou, D., Louri, H., and Tsionas, M. G. (2016). Non-performing loans in the euro area: Are core-periphery banking markets fragmented? Working Paper No. 219, Bank of Greece, Athens.

Angelini, P, Nobili, A., and Picillo, C. (2011). "The interbank market after August 2007: What has changed, and why?" Journal of Money, Credit and Banking, 43, no. 5, 923-958.

Arellano, M. (1987). "Computing robust standard errors for within-groups estimators." Oxford Bulletin of Economics and Statistics, 49, no. 4, 431-434.

Baele, L., Bekaert, G., and Inghelbrecht, K. (2010). "The determinants of stock and bond return comovements." The Review of Financial Studies, 23, no. 6, 2374-2428.

Baele, L., Ferrando, A., Hördahl, P., Krylova, E., amd Monnet, C. (2004). Measuring financial integration in the euro area, Occasional Paper No. 14, European Central Bank.

Baltagi, B. H., Demetriades, P. O., and Law, S. H., (2009). "Financial development and openness: Evidence from panel data." Journal of Development Economics, 89, no. 2, 285-296.

Barth, J. R., and Levine, R. (2013). "Bank regulation and supervision in 180 countries from 1999 to 2011." Journal of Financial Economic Policy, 5, no. 2, 111-219. 
Battistini, N., Pagano, M., and Simonelli, S. (2013). Systemic risk and home bias in the euro area (No. 494). Directorate General Economic and Financial Affairs (DG ECFIN), European Commission.

Bayoumi, T., and B. Eichengreen (1993). Shocking aspects of European Monetary integration: Adjustment and growth in the European monetary union. Cambridge: Cambridge University Press.

Beine, M., Cosma, A., and Vermeulen, R. (2010). "The dark side of global integration: Increasing tail dependence." Journal of Banking and Finance, 34, no. 1, 184-192.

Belke, A., Domnick C., and Gros D. (2017). "Business cycle synchronization in the EMU: Core vs. periphery." Open Economies Review, 28, 863-892.

Bekaert, G., Ehrmann, M., Fratzscher, M., and Mehl, A.J. (2014). "Global crisis and equity market contagion." J. Finance 69, no. 6, 2597-2649.

Bondt, G. (2005). "Interest rate pass-through: Empirical results for the euro area." German Economic Review, 6, 37-78.

Borio, C., and Lowe, P. (2002). "Assessing the risk of banking crises." BIS Quarterly Review, 7, no. $1,43-54$.

Bouvatier, V., and Delatte, A. L. (2015). "Waves of international banking integration: A tale of regional differences." European Economic Review, 80, 354-373.

Boyd, J. H., and Smith, B. D. (1992). "Intermediation and the equilibrium allocation of investment capital: Implications for economic development." Journal of Monetary Economics, 30, no. 3, 409-32.

Bracker, K., and Koch, P. D. (1999). "Economic determinants of the correlation structure across international equity markets." Journal of Economics and Business, 51, no. 6, 443-471.

Buch, C. M., Körner, T., and Weigert, B. (2015). "Towards deeper financial integration in Europe: What the banking union can contribute." Credit and Capital Markets-Kredit und Kapital, 48, no. 1, 11-49.

Buttner, D., and Hayo, B. (2010). "News and correlations of CEEC-3 financial markets." Economic Modelling, 27, 915-922.

Cabral I., Dierick F., and Vesala, J. (2002). Banking integration in the Euro Area. Occasional Paper Series No. 6, European Central Bank.

Campos, N. F., and Macchiarelli, C. (2016). "Core and periphery in the European monetary union: Bayoumi and eichengreen 25 years later." Economics Letters, 147, 127-130.

Cappiello L., Engle R.H., and Sheppard K. (2006) "Asymmetric dynamics in the correlations of global equity and bond returns." Journal of Financial Econometrics, 4, 537-72.

Cerqueira, P. A. (2013). "A closer look at the world business cycle synchronization." International Economics and Economic Policy, 10, no. 3, 349-363.

Christoffersen, P., Errunza, V., Jacobs, K., and Langlois, H. (2012). "Is the potential for international diversification disappearing? A dynamic copula approach.” Rev. Financ. Stud. 25, no. 12, 3711-3751.

Clark, T. E., and Van Wincoop, E. (2001). "Borders and business cycles." Journal of International Economics, 55, no. 1, 59-85.

De Santis, R., and Cesaroni, T. (2016). "Current account 'Core-Periphery Dualism' in the EMU." The World Economy, 39, no. 10, 514-1538.

Dungey, M., and Gajurel, D. (2015). "Contagion and banking crisis - International evidence for 2007-2009." Journal of Banking \& Finance, 60, 271-283. 
ECB. (2017). Financial integration in Europe. Frankfurt am Main.

Eppendorfer, C., Beckmann, R., and Neimke, M. (2003). "Market Access Strategies in the EU Banking Sector-Obstacles and Benefits towards an Integrated European Retail Market: The Incomplete European Market for Financial Services. Heidelberg: Physica-Verlag.gorton.

Eun, C. S., and Lee, J. (2010). "Mean-variance convergence around the world." Journal of Banking and Finance, 34, no. 4, 856-870.

Eurobarometer. (2012). Europeans and Their Languages, Special Eurobarometer Report 386. European Commission. http://ec.europa.eu/public_opinion/archives/ebs/ebs_386_en.pdf.

Fecht, F., Grüner, H. P., and Hartmann, P. (2012). "Financial integration, specialization, and systemic risk." Journal of International Economics, 88, no. 1, 150-161.

Goddard, J., Molyneux, P., Wilson, J. O., and Tavakoli, M. (2007). "European banking: An overview." Journal of Banking \& Finance, 31, 1911-1935.

Goldberg, L. (2009). Understanding banking sector globalization. IMF Staff Papers No. 56, International Monetary Fund.

Gorton, G. B., Metrick, A., and Xie, L. (2014). The flight from maturity (No. w20027). National Bureau of Economic Research.

Grammatikos, T., and Vermeulen, R. (2012). "Transmission of the financial and sovereign debt crises to the EMU: Stock prices, CDS spreads and exchange rates." Journal of International Money and Finance, 31, no. 3, 517-533.

Gropp, R., Kok, C., and Lichtenberger, J. D. (2014). "The dynamics of bank spreads and financial structure." The Quarterly Journal of Finance, 4, no. 4, 1450014.

Gupta, P., Sehgal, S., and Deisting, F. (2015). "Time-Varying bond market integration in EMU." Journal of Economic Integration, 708-760.

Hodcrick, R. J., and Prescott, E. C. (1997). "Postwar US business cycles: an empirical investigation." Journal of Money, credit, and Banking, 1-16.

Hooy, C. W., and Goh, K. L. (2007). "The determinants of stock market integration: A panel data investigation: Proceedings of the 15th Annual Conference on Pacific Basin Finance", Economics, Accounting and Management, 1-32.

Kim, S. J., Moshirian, F., and Wu, E. (2005). "Dynamic stock market integration driven by the European monetary union: An empirical analysis.” Journal of Banking and Finance, 29, no. 10, 2475-2502.

Kleimeier S., and Sander, H. (2006). "Regional versus global integration of euro-zone retail banking markets: Understanding the recent evidence from price-based integration measures." The Quarterly Review of Economics and Finance 46, 353-368.

Kogut, B., and Singh, H. (1988). "The effect of national culture on the choice of entry mode." Journal of international business studies, 19, no. 3, 411-432.

Kotkatvuori-Örnberg, J. (2016). "Dynamic conditional copula correlation and optimal hedge ratios with currency futures." International Review of Financial Analysis, 47, no. C, 60-69.

Lucey, B. M., and Zhang, Q. (2011). "Financial integration and emerging markets capital structure." Journal of Banking \& Finance, 35, no. 5, 1228-1238.

Kratochvíl, P., and Sychra, Z. (2019). "The end of democracy in the EU? The Eurozone crisis and the 
EU's democratic deficit." Journal of European Integration, 1-17.

Martın-Oliver, A., Saurina, J., and Salas-Fuma, V. (2005). Interest rate dispersion in deposit and loan markets. Working Paper No. 0506, Banco de España.

Mayordomo, S., Abascal, M., Alonso, T., and Rodriguez-Moreno, M. (2015). "Fragmentation in European financial markets: Measures, determinants, and policy solutions”, Journal of Financial Stability, 16, $1-12$.

Mobarek, A., Muradoglu, G., Mollah, S., and Hou, A. J. (2016). "Determinants of time-varying comovements among international stock markets during crisis and non-crisis periods.” Journal of Financial Stability, 24, $1-11$.

Narayan, S., Sriananthakumar, S., and Islam, S. Z. (2014). "Stock market integration of emerging Asian economies: Patterns and causes." Economic Modelling, 39, 19-31.

Obstfeld, M. (1998). “The global capital market: benefactor or menace?” Journal of Economic Perspectives, 12, no. $4,9-30$.

Patton, A. J. (2006). "Modeling asymmetric exchange rate dependence." International economic review, 47 , no. 2, 527-556.

Pagano, M. (1993). "Financial markets and growth: An overview." European Economic Review, 37, 613-622.

Perego, E. R., and Vermeulen, W. N. (2016). "Macro-economic determinants of European stock and government bond correlations: A tale of two regions." Journal of Empirical Finance, 37, 214-232.

Perez, D., Vicente, S.F., and Saurina, J. (2005). Banking integration in Europe. Working Paper 0519, Banco De España, 1-41.

Philippas, D., and Siriopoulos, C. (2013). "Putting the "C" into crisis: Contagion, correlations and copulas on EMU bond markets.“ Journal of International Financial Markets, Institutions and Money, 27, 161-176.

Piljak, V. (2013). "Bond markets comovement dynamics and macroeconomic factors: Evidence from emerging and frontier markets." Emerging Markets Review, 17, 29-43.

Popov, A., and Ongena, S. (2011). "Interbank market integration, loan rates and firm leverage." Journal of Banking \& Finance 35, 544-559.

Quinn, D.P., amd Toyoda, A.M. (2008). "Does Capital Account Liberalization Lead to Economic Growth?" Review of Financial Studies, 21, no. 3, 1403-1449.

Rughoo, A., and Sarantis, N. (2012) "Integration in European retail banking: Evidence from savings and lending rates to non-financial corporations." Journal of International Financial Markets, Institutions and Money, 22, 1307-1327.

Rughoo, A., and Sarantis, N. (2014) "The global financial crisis and integration in European retail banking." Journal of Banking and Finance, 40, 28-41.

Schmitz, B., and Von Hagen, J. (2011). "Current account imbalances and financial integration in the euro area." Journal of International Money and Finance, 30, no. 8, 1676-1695.

Sehgal, S., Gupta, P., and Deisting, F. (2016). "Integration from retail banking to non-financial corporations in EMU." Journal of Economic Integration, 31, no. 3, 674-735.

Sehgal, S., Pandey, P., and Deisting, F. (2018). "Stock market integration dynamics and its determinants 
in the East Asian economic community region." Journal of Quantitative Economics, 31, no. 3, 674-735. Sklar, A. (1959). "Fonctions de répartition à n dimensions et leurs marges." Institut Statistique de l'Université de Paris, 8, 229-231.

Sørensen, C. K., and Puigvert Gutiérrez, J. M. (2006). Euro area banking sector integration: using hierarchical cluster analysis techniques. Working Paper Series 627, European Central Bank.

Stock, J., and Watson, M. (2006). Heteroskedasticity-Robust Standard Errors for Fixed Effects Panel Data Regression." Technical Report 0323, NBER Working Paper Series.

Van Rijckeghem, C., and Weder, B., (2003). "Spillovers through banking centers: A panel data analysis of bank flows." J. Int. Money Finance 22, no. 4), 483-509.

Wälti, S. (2011). "Stock market synchronization and monetary integration." Journal of International Money and Finance, 30, no. 1, 96-110.

Weiß, G. N., Bostandzic, D., and Neumann, S. (2014). "What factors drive systemic risk during international financial crises?” Journal of Banking \& Finance, 21, 78-96. 